\title{
1 Trace impurities in test stimuli can seriously compromise chemosensory
}

2

3

\section{studies}

Dirk Louis P. Schorkopf ${ }^{1,2,}$, Béla Péter Molnár ${ }^{3}$, Marit Solum $^{1}$, Mattias C. Larsson ${ }^{1}$, Jocelyn G. Millar ${ }^{4}$, Zsolt Kárpáti $^{3 \mathrm{~b}}$, Teun Dekker ${ }^{1, \S \mathbf{b}}$

${ }^{\S}$ Corresponding authors: Dirk.Louis.Research@outlook.com, teun.dekker@ slu.se

${ }^{1}$ Department of Plant Protection Biology, Division of Chemical Ecology, Swedish University of Agricultural Sciences, Alnarp, Sweden

${ }^{2}$ Sørengkaia 115, 0194 Oslo, Norway

${ }^{3}$ Zoology Department, Plant Protection Institute, Centre for Agricultural Research, Hungarian Academy of Sciences, Budapest, Hungary

${ }^{4}$ Departments of Entomology and Chemistry, University of California, Riverside CA 92521, USA

${ }^{\mathrm{b}}$ shared last authorship

Keywords: chemosensation, olfaction, chemoreceptor, purity, Drosophila, sensitivity, Bombyx mori

The discovery of olfactory receptors and major technological advances have greatly accelerated our understanding of chemosensory mechanisms. However, some of this rapid progress may be compromised by inadequate knowledge or characterization of the purity of chemical stimuli used to challenge olfactory or other chemoreceptors when mapping their response profiles. Here, we provide strong evidence that the presence of trace impurities in test stimuli can completely obscure true ligand-receptor relationships. DmOR7a, an olfactory receptor of the vinegar fly (Drosophila melanogaster) has been reported to respond to several long-chain aliphatic ligands such as a putative Drosophila pheromone ${ }^{1}$, the pheromone of the silkworm moth Bombyx mori ${ }^{2}$, and a common fatty acid, linoleic acid ${ }^{3}$. By contrast, we show that DmOR7a responds with high sensitivity to volatile impurities and degradation products present in minute quantities in authentic standards of those 
compounds, but not to the standards themselves. Responses to impurities can easily go unnoticed due

to two main factors. First, the sensitivity of receptors to key ligands may be greater than that of analytical chemistry instruments used to check sample purity. Second, the concentration of highly volatile impurities in an odour puff may be orders of magnitude higher than the main component of a sample, due to the large differences in vapour pressures between the impurities and the main component. Issues concerning impurities are not limited to studies on olfaction that use odour puffs to characterize receptor-ligand interactions, but may affect all studies on chemosensation, from molecular biology and in-silico predictions to behaviour. Purity, which is crucial in receptor-ligand studies, is always implied, but rarely checked rigorously. To avoid misinterpretations, a proper account of all compounds present in test stimuli and an unequivocal confirmation of ligand affinity should accompany chemosensory studies.

The field of chemosensory sciences has progressed rapidly through molecular, genetic, and neurophysiological advances that permit the unravelling of the full sequence from perireceptor events to receptor-induced intracellular responses, downstream neuronal signalling and processing in the brain, and ultimately behavioural output ${ }^{4-8}$. A commonplace assumption in these studies is that standards used as chemosensory stimuli are pure, or alternatively, that observed responses are the result of interactions between the receptor and the nominal authentic standard.

In routine evaluations of $D$. melanogaster olfactory receptor $(\mathrm{OR})$ affinities, we observed that $A B 4 a$ neurons housed in antennal basiconic sensilla responded differently than anticipated. This neuron and its endogenous receptor DmOR7a are reported to be broadly sensitive to short-chain six-carbon aldehydes, alcohols, and esters ${ }^{9}$, but also to longer chain compounds, such as the silk moth pheromone, bombykol ((10E,12Z)-10,12-hexadecadien-1-ol $)^{2,10}$, the Drosophila cuticular hydrocarbon, (Z)-9-tricosene (Z9T) ${ }^{1}$, 
51 lost activity with repeated puffs (Extended Data Fig. 1c, and Extended Data Fig. 2c). This was unexpected,

52 because these long-chain compounds have low vapour pressures and would be expected to deliver a

53 relatively constant stimulus dose over numerous puff cycles $^{11-13}$. Indeed, such declines were not observed

54 (Extended Data Fig. 1a,b) when using the same protocol to stimulate the pheromone receptor of B. mori,

55 BmOR $1^{14}$ (exogenously expressed in D. melanogaster $\mathrm{T} 1$ neurons, $\mathrm{T} 1_{\mathrm{BmOR} 1}$ ) with bombykol, or when

56 stimulating wildtype T1 neurons (expressing its cognate receptor DmOR67d ${ }^{15}$ ) with its ligand, the long-

57 chain Drosophila pheromone $c$ is-vaccenyl acetate ((Z)-11-octadecenyl acetate; $c$ VA).

Furthermore, AB4a neurons responded equally well to bombykol on a filter paper or in paraffin oil ${ }^{11}$

(Extended Data Fig. 3a). This was counterintuitive, because non-volatile paraffin oil should retain

bombykol, a long-chain aliphatic compound, and significantly reduce volatilization and hence stimulus

61 intensity compared to bombykol applied to filter paper ${ }^{11,13}$. Indeed, responses of antennal trichoid T1

62 (sensitive to $c \mathrm{VA}$ ) and $\mathrm{T} 1_{\mathrm{BmOR} 1}$ neurons (sensitive to bombykol) were significantly attenuated when

63 stimulated with air puffed over dilutions of $c \mathrm{VA}$ or bombykol dissolved in paraffin oil versus on filter paper

64 (Extended Data Fig. 3b, c).

This cast doubt on whether the above-mentioned compounds were indeed ligands for AB4a neurons. To more rigorously test this, we used coupled gas chromatography-electroantennographic detection (GCEAD), which separates the injected sample into its individual components and sequentially passes these over the antennal preparation. Thus, each antennal response can be unequivocally attributed to a defined peak, which generally represents a single pure compound. We found that the cleanly separated bombykol peak did not induce antennal depolarization in wildtype fly antennae (Fig. 1a; Extended Data Fig. 4 and 5), nor did bombykal (another reported ligand for AB4a neurons) ${ }^{2,10}$, Z9T, or LLA (Fig. 1b, Extended Data Fig. 5). The GC-EAD setup was clearly functioning properly because antennae of male $B$. mori responded strongly to bombykol (Fig. 1c), as did antennae of D. melanogaster expressing the bombykol receptor BmOR1 in T1 neurons (Fig. 1a). Wildtype fly antennae also responded as expected to $c$ VA (Fig. 1, Extended Data Fig. 4). 
77 Whereas bombykol did not elicit responses from wildtype antennae, responses were elicited by several 78 impurities that eluted much earlier than bombykol (Fig. 1, R1 and R2). Using coupled GC-single-sensillum recordings (GC-SSR), we challenged AB4 sensillum preparations sequentially with these impurities. The above two low-molecular-weight impurities (R1 and R2) in the bombykol and bombykal samples induced strong responses in AB4a neurons (Fig. 2a). Coupled GC-mass spectrometry subsequently identified these as $(E)$-2-hexenal $(\mathrm{E} 2 \mathrm{H})$ and $(\mathrm{Z})-2$-hexenal $(\mathrm{Z} 2 \mathrm{H})$. E2H is a known ligand for AB4a neurons and their cognate receptor DmOR7 ${ }^{9}$. Puffs from cartridges loaded with 2-hexenal in amounts corresponding to those in our bombykol sample induced antennal responses comparable to those seen with our bombykol sample (Fig. 2b). We further tested the role of 2-hexenal by removing $\mathrm{E} 2 \mathrm{H}$ and $\mathrm{Z} 2 \mathrm{H}$ from the sample, predicting that this would significantly reduce the responses of $\mathrm{AB} 4 \mathrm{a}$ neurons. Thus, reduction of the sample with

87 sodium borohydride, which reduces $\mathrm{E} 2 \mathrm{H}$ and $\mathrm{Z} 2 \mathrm{H}$ to the far less stimulatory ${ }^{9}$ alcohols $(E)$ - and $(Z)-2$ -

88 hexenol, dramatically attenuated the responses of $\mathrm{AB} 4 \mathrm{a}$ neurons, as did reduction of synthetic E2H itself

89 (Fig. 3a, b). E2H may arise from oxidative degradation of bombykol and bombykal at carbon 10, similar to oxidative degradation of unsaturated fatty acids ${ }^{16}$. Interestingly, a freshly synthesized batch of bombykol obtained from the same company contained significantly less E2H than the original sample, and accordingly induced lower responses from AB4a neurons (Extended Data Fig. 2c, 6).

We subsequently assessed whether samples of LLA and Z9T also contained E2H or other AB4a-stimulating impurities. Indeed, GC-SSR analyses of LLA and Z9T samples showed responses from AB4a neurons at the retention time of E2H (Extended Data Fig. 7), although weaker than bombykol, likely due to the substantially lower amounts of E2H in the samples (Extended Data Figs. 8). Similar to bombykol, Z9T

97 samples from two different suppliers elicited markedly different response amplitudes from AB4a neurons

98 (Extended Data Fig. 2a,b), suggesting that impurities, rather than Z9T itself, induced the responses. This is underscored by the fact that $\mathrm{AB} 4 \mathrm{a}$ neurons responded more strongly to puffs of synthetic $(Z)$-7-tricosene (Z7T) than Z9T (Extended Data Fig. 2a), likely because this sample contained $\sim 10$-fold more E2H than 
either of the Z9T samples. Z7T is a male cuticular pheromone of D. melanogaster ${ }^{17,18}$ and present in much higher amounts than $\mathrm{Z9T}^{18}$, but was excluded in the electrophysiological evaluations of the abovementioned study ${ }^{1}$. Finally, we assessed whether AB4a neurons responded to biological samples containing Z9T: odour puffs from a cartridge loaded with a cuticular extract from 350 (mixed sex) or 70 Drosophila

105 (separated sexes) containing up to $\sim 15 \mu \mathrm{g}$ of Z9T, did not elicit significant responses (Extended Data Fig.

106 9). None of the above observations fit with a Z9T-mediated role for AB4a neurons in aggregation and 107 oviposition ${ }^{1}$, but instead show that AB4a neurons respond to impurities in synthetic Z9T samples, rather 108 than to Z9T itself.

In the above analyses, each of the synthetic samples contained approximately 5\% impurities constituting numerous tiny peaks (e.g. Fig. 1, Fig. 4), and sensory neurons appeared extraordinarily sensitive to some 111 of these trace impurities, even when below the GC detection threshold ( 1 picogram $\left.{ }^{11,13}\right)$. Thus, standard 112 GC analysis may not suffice for detection of confounding impurities in samples.

114 puffing, the transition of compounds from the liquid to the vapour phase is largely dependent on their 115 vapour pressures ${ }^{11,13}$. Accordingly, the relative proportions of compounds in the vapour may be massively 116 different than their proportions in the liquid phase. For example, because the calculated vapour pressure of 117 E2H at $25^{\circ} \mathrm{C}$ is $629 \mathrm{~Pa}$, versus $7.59 \times 10^{-4} \mathrm{~Pa}$ for bombykol (Supplementary Table 5, Extended Data Fig. $11810^{19}$ ), the headspace above a sample of bombykol containing $0.1 \% \mathrm{E} 2 \mathrm{H}$ would contain far more E2H than 119 bombykol. Consequently, the composition of the bulk sample may be entirely unrepresentative of the 120 composition of the headspace used for stimulation. Indeed, the headspace of bombykol, Z9T, LLA and $121 \mathrm{cVA}$, sampled with Solid Phase Microextraction (SPME) ${ }^{20}$, was dominated by numerous volatile impurities 122 (Fig. 4, Extended Data and Supplementary Tables 1-4), whereas the main compound was barely detectable. 123 Many impurities in the headspace of samples elicited consistent EAD responses (Fig. 4, Extended Data 124 Tables 1-4), among which were several ligands for receptors other than DmOR7a. 
125 It is common practice in chemoreceptor studies to prepare panels of chemical species at fixed amounts or 126 concentrations so to assign ligands to receptors, sensory neurons, processing networks and behaviour ${ }^{9,11}$. In 127 addition to the potentially confounding impurities present in synthetic standards, we emphasize that the 128 precise amount and ratio of molecules reaching the target might vastly differ from the prepared/intended 129 amount ${ }^{11}$ if factors such as different vapour pressures or solubility are neglected.

130 Importantly, impurities can affect chemosensory studies even when a compound has been unequivocally 131 linked to a target neuron. For instance, in our study, all the synthetic samples contained impurities that 132 induced responses in sensory neuron types other than AB4a neurons (see Fig. 4a and Extended Tables 1$1334^{9}$ ). The above samples thus stimulated non-target sensory neurons with unknown effects on downstream 134 neural integration and behavioural output ${ }^{21}$.

135 In the present study, a single neuron-receptor combination, AB4a-DmOR7a, served to illustrate how the 136 extraordinary sensitivity of receptors to their key ligands, vast differences in vapour pressures between a 137 putative test chemical and its impurities, or a combination thereof ${ }^{11,22-24}$ can skew or even completely 138 confound the results of otherwise elegantly crafted studies. This issue of impurities is ubiquitous and 139 pernicious, potentially affecting any study involving chemoreceptors and sensory neurons, and the correct 140 interpretation of downstream neuronal outputs, signal integration in the brain, and finally behavioural 141 responses. To minimize errors due to impurities and more reliably correlate ligands with their receptors, 142 neural circuits and behaviour, we advocate using methods such as GC-EAD or GC-SSR which separate out 143 impurities and deliver known amounts of pure ligands to their targets. 


\section{Acknowledgements}

147 We thank Prof. W. Francke for comments during data collection and writing, Prof. Walter Leal for BmOR1 148 Drosophila lines, and Prof. Barry Dickson for the DmOR67D-Gal4 Drosophila line. The research was 149 supported by the following grants: $\mathrm{ICE}^{3}$ (a Linnaeus grant to the unit of Chemical Ecology, DLPS, MS, 150 MCL, TD), Vetenskapsrådet (621-2014-4816, TD), TASENE (a grant for research collaboration with 151 Tanzania, Tasene/Sida/2/2012, DLPS), Carl-Fredrik von Horns fund of the Royal Swedish Academy of 152 Agriculture and Forestry (H11-0195-CFH-01, DLPS), Guest Scientists Fellowship Programme of the 153 Hungarian Academy of Sciences (VK-003/2016, TD, ZK), Hungarian Scientific Research Fund - NKFIH 154 (K 119844, ZK, BPM), National Research, Development, and Innovation Office (GINOP-2.3.2-15-2016155 00051, ZK, BPM).

156 Author Contributions Conceived the original idea of the significance of impurities in chemosensory 157 studies (TD), initiated, conceptualized and coordinated the research (DLPS, TD), designed the experiments 158 (DLPS, MS, MCL, BPM, ZK, TD), executed the experiments (DLPS, MS, MCL, BPM, JM, ZK, TD), 159 analyzed chemical data and identified impurities (DLPS, BPM, JM), analyzed physiological data (DLPS, 160 BPM, ZK, TD), performed statistics (DLPS), wrote initial versions of the manuscript (DLPS, TD), 161 commented and improved the manuscript (DLPS, MS, MCL, BM, JM, ZK, TD).

162 Competing interests The authors declare no competing interests.

163 Extended data is available. [to be filled in after acceptance for publication]

164 Supplementary information is available. [to be filled in after acceptance for publication]

165 Reprints and permissions information [to be filled in after acceptance for publication] 


\section{REFERENCES}

167

1. Lin, C. C., Prokop-Prigge, K. A., Preti, G. \& Potter, C. J. Food odors trigger Drosophila males to deposit a pheromone that guides aggregation and female oviposition decisions. Elife 4, e08688 (2015).

2. Syed, Z., Ishida, Y., Taylor, K., Kimbrell, D. A. \& Leal, W. S. Pheromone reception in fruit flies expressing a moth's odorant receptor. Proc. Natl. Acad. Sci. 103, 16538-16543 (2006). (2006).

4. Hansson, B. S. \& Stensmyr, M. C. Evolution of insect olfaction. Neuron 72, 698-711 (2011).

5. Leal, W. S. Odorant reception in insects: roles of receptors, binding proteins, and degrading enzymes. Annu. Rev. Entomol. 58, 373-391 (2013). ecologically relevant signals driving behavior in Drosophila. Front. Ecol. Evol. 3, (2015).

7. Mansourian, S. \& Stensmyr, M.C. The chemical ecology of the fly. Curr. Opin. Neurobiol. 34, 95-102 (2015).

8. Grabe, V. et al. Elucidating the neuronal architecture of olfactory glomeruli in the Drosophila antennal lobe. Cell Rep. 16, 3401-3413 (2016).

9. Münch, D. \& Galizia, C. G. DoOR 2.0 - Comprehensive mapping of Drosophila melanogaster odorant responses. Sci. Rep. 6, 21841 (2016).

10. Syed, Z., Kopp, A., Kimbrell, D. A. \& Leal, W. S. Bombykol receptors in the silkworm moth and the fruit fly. Proc. Natl. Acad. Sci. 107, 9436-9439 (2010). calibrate odor flux and ligand-receptor affinities. Chem. Senses 37, 403-420 (2012). 
12. Kárpáti, Z., Tasin, M., Cardé, R. T. \& Dekker, T. Early quality assessment lessens pheromone specificity in a moth. Proc. Natl. Acad. Sci. 110, 7377-7382 (2013).

13. Tasin, M., Cappellin, L. \& Biasioli, F. Fast direct injection mass-spectrometric characterization of stimuli for insect electrophysiology by proton transfer reaction-time of flight mass-spectrometry (PTR-ToF-MS). Sensors 12, 4091-4104 (2012).

14. Nakagawa, T., Sakurai, T., Nishioka, T. \& Touhara, K. Insect sex-pheromone signals mediated by specific combinations of olfactory receptors. Science 307 (5715), 1638-1642 (2005).

15. Ha, T. S. \& Smith, D.P. Pheromone receptor mediates 11-cis-vaccenyl acetate-induced responses in Drosophila. J. Neurosci. 26, 8727-8733 (2006).

16. Frankel, E. N. Lipid Oxidation. (Woodhead Publishing, Cambridge, 2005).

17. Grillet, M., Dartevelle, L. \& Ferveur, J. F. A Drosophila male pheromone affects female sexual receptivity. Proc. $R$. Soc. B 273, 315-323 (2006).

18. Farine, J. P., Ferveur, J. F. \& Everaerts, C. Volatile Drosophila cuticular pheromones are affected by social but not sexual experience. PLoS One 7, e40396 (2012). (Gulf Professional Publishing, Amsterdam, 2015).

20. Spietelun, A., Pilarczyk, M., Kloskowski, A. \& Namieśnik, J. Current trends in solid-phase microextraction (SPME) fibre coatings. Chem. Soc. Rev. 39, 4524-4537 (2010).

21. Das, S. et al. Electrical synapses mediate synergism between pheromone and food odors in Drosophila melanogaster. Proc. Natl. Acad. Sci. 114, E9962-E9971 (2017).

22. Stensmyr, M. C. et al. A conserved dedicated olfactory circuit for detecting harmful microbes in Drosophila. Cell 151, 1345-1357 (2012).

23. Paoli, M. et al. Minute impurities contribute significantly to olfactory receptor ligand studies: tales from testing the vibration theory. Eneuro 4, ENEURO.0070-17.2017 (2017). 
24. Choo, Y.-M. et al. Reverse chemical ecology approach for the identification of an oviposition
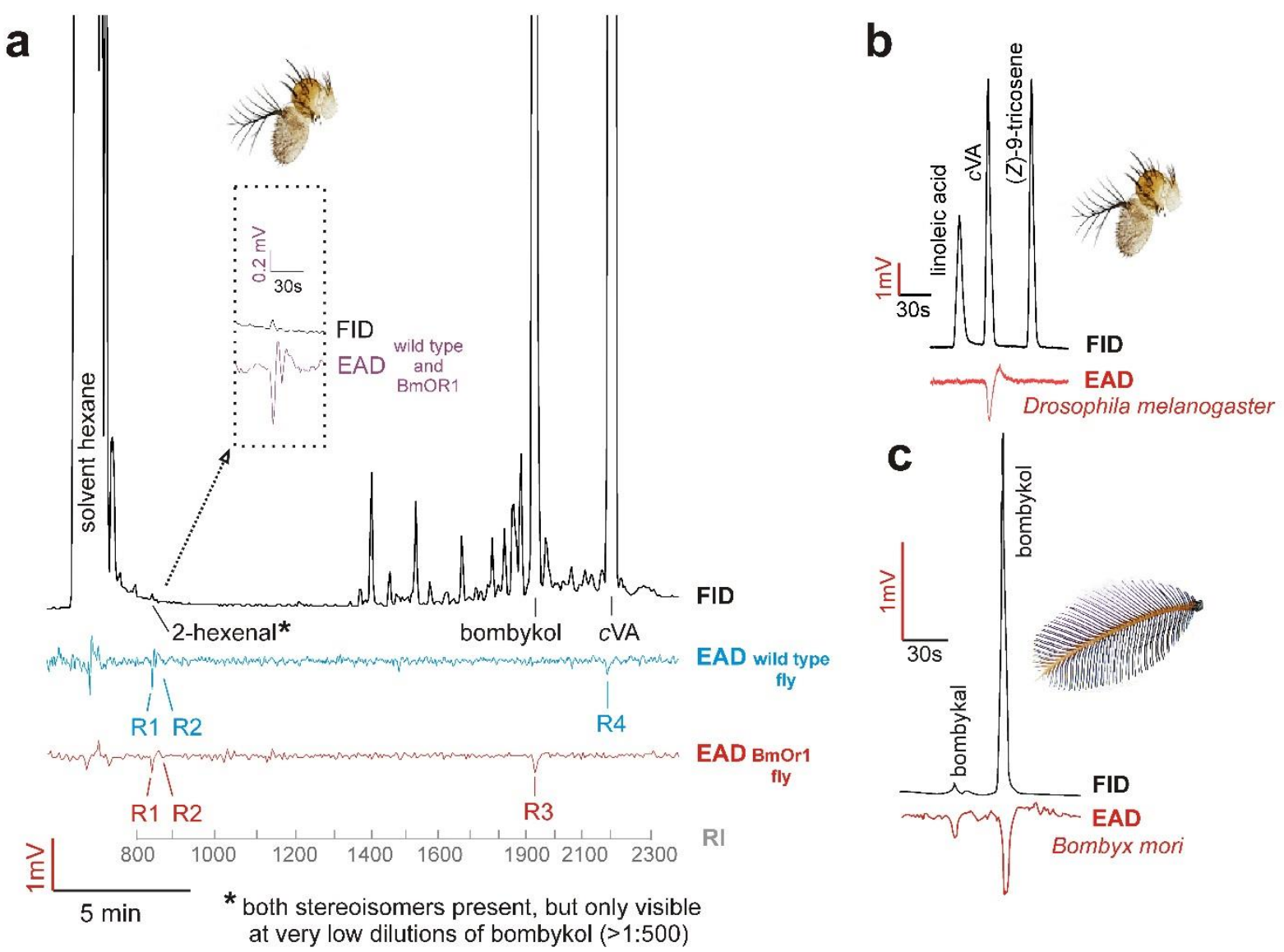

Figure 1 | Representative responses of whole mount fly and moth antennal preparations to compounds 

responded to bombykol and bombykal $(n=5)$.

a

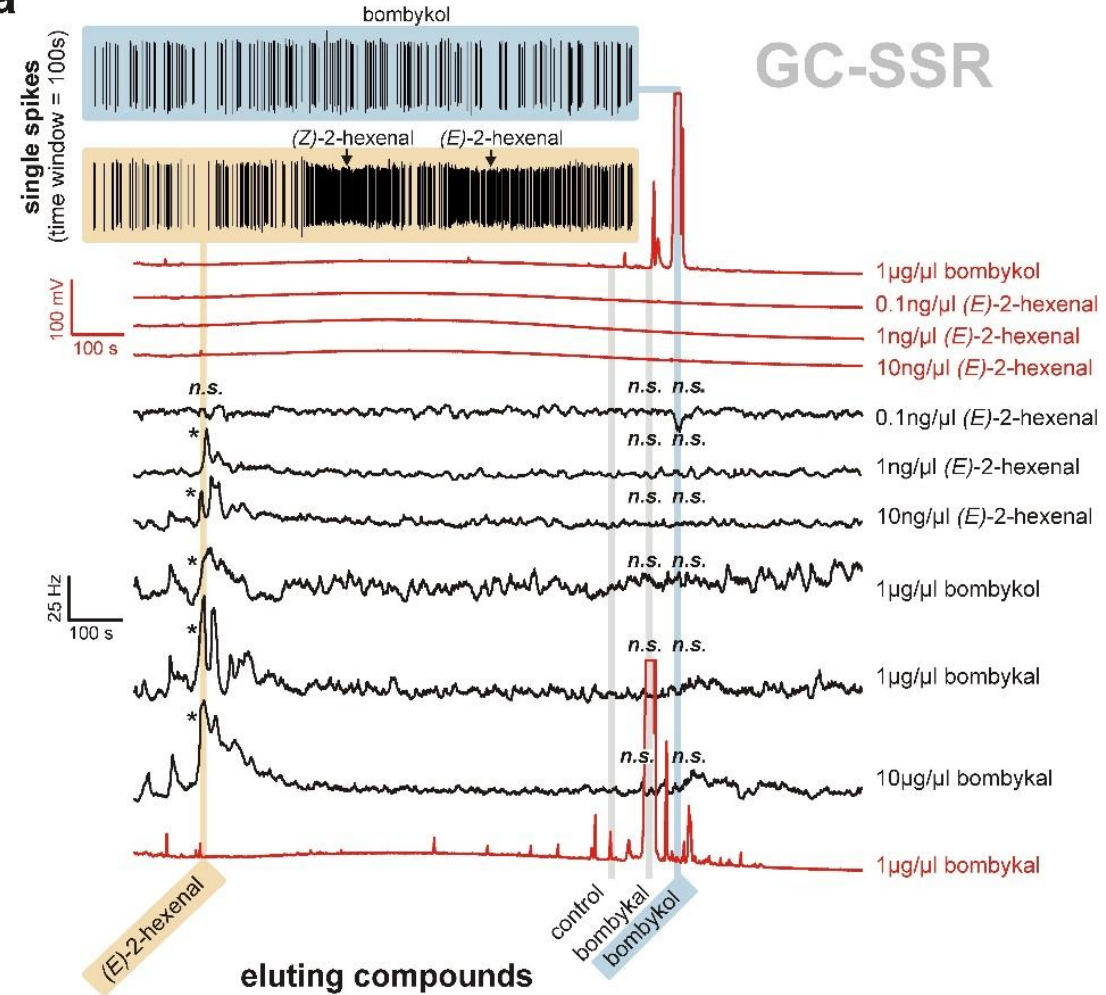

b
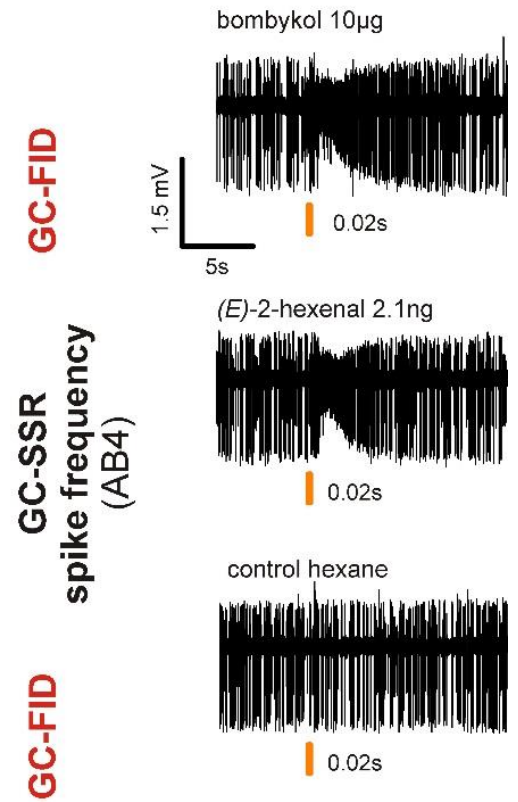

Figure 2 | Responses of Drosophila antennal basiconic 4a neurons to bombykol, bombykal, and E2H.

A, Responses of AB4a neurons to chromatographically separated dilutions of synthetic standards of bombykol, E2H, and bombykal. Whereas the peaks from pure bombykol or bombykal never induced a response (top blue trace), E2H did (yellow example trace), at all concentrations above $0.1 \mathrm{ng} / \mu \mathrm{l}$. In red: GC-FID traces, in black: responses of AB4A neuron converted to Hz. B, Single sensilla were treated with puffs from cartridges loaded with either bombykol or E2H (loaded with amounts equivalent to the amount of E2H impurity in the bombykol standard), eliciting comparable neuronal responses. Asterisks (*) indicate 
a

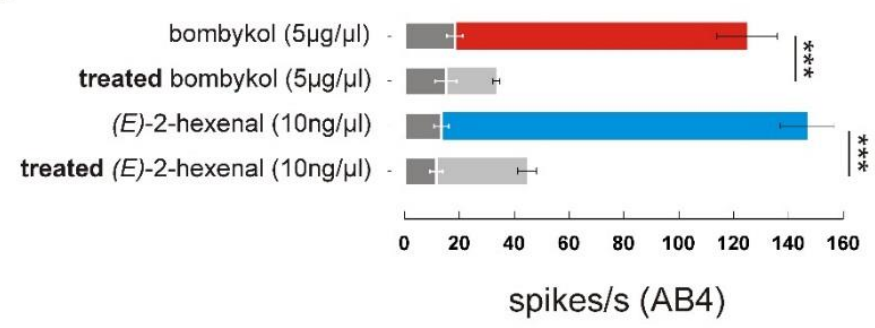

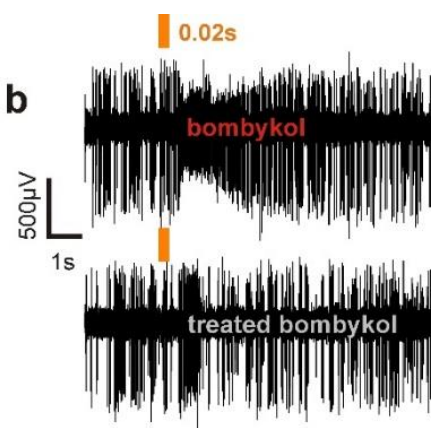

Figure 3 | Chemically reducing C6 aldehydes to alcohols eliminated responses (means $\pm 95 \% \mathrm{CI}$ ) of antennal basiconic 4a neurons that were typically elicted by the untreated synthetic bombykol and

E2H (see also fig. 2B). A, Puffs with the synthetic standard after reduction with sodium borohydride, which converted $\mathrm{E} 2 \mathrm{H}$ and $\mathrm{Z} 2 \mathrm{H}$ to the corresponding alcohols, elicited dramatically attenuated responses to the

247 reduced products. Reducing synthetic E2H under the same conditions gave analogous results. Overlaid dark

248 grey bars with white whiskers show the results obtained for the pre-puffing control periods. Asterisks (***)

249 indicate highly significant differences (paired t-test, $n=8$ different flies, $p<0.001$ ). $\mathbf{B}$, Example traces of

250 stimulation of the AB4a neuron with synthetic bombykol before (top) and after (bottom) sodium

251 borohydride treatment. 
a

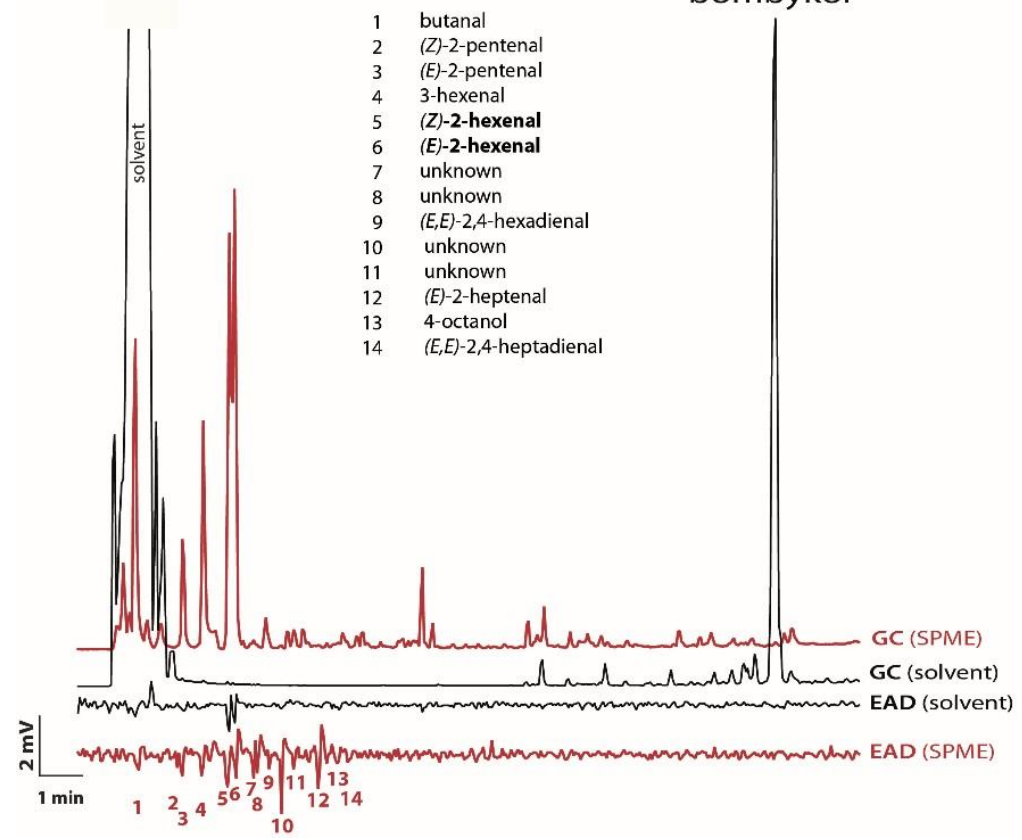

b

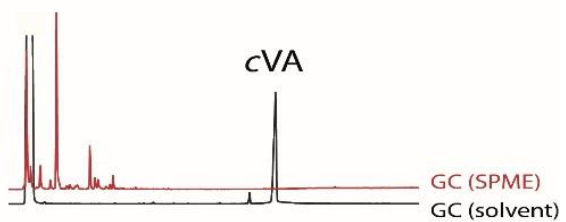

C
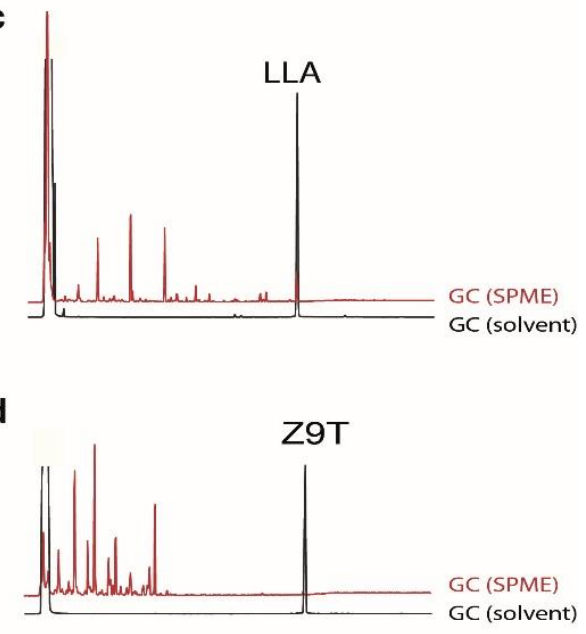
impurities, but the concentrations of volatile impurities can be orders of magnitude greater in the headspace above the liquid samples (red, sampled using SPME), as illustrated with the synthetic standard of bombykol. Accordingly, antennae may respond to confounding impurities in headspace samples (red) much more intensely than when samples are injected as solutions (black), as exemplified with bombykol. B, C and D illustrate the same phenomenon with standards of $c \mathrm{VA}$, LLA, and Z9T, in which the concentrations of volatile impurities in the headspace are magnified enormously relative to the main component, in comparison to the concentrations in the bulk samples. 
a

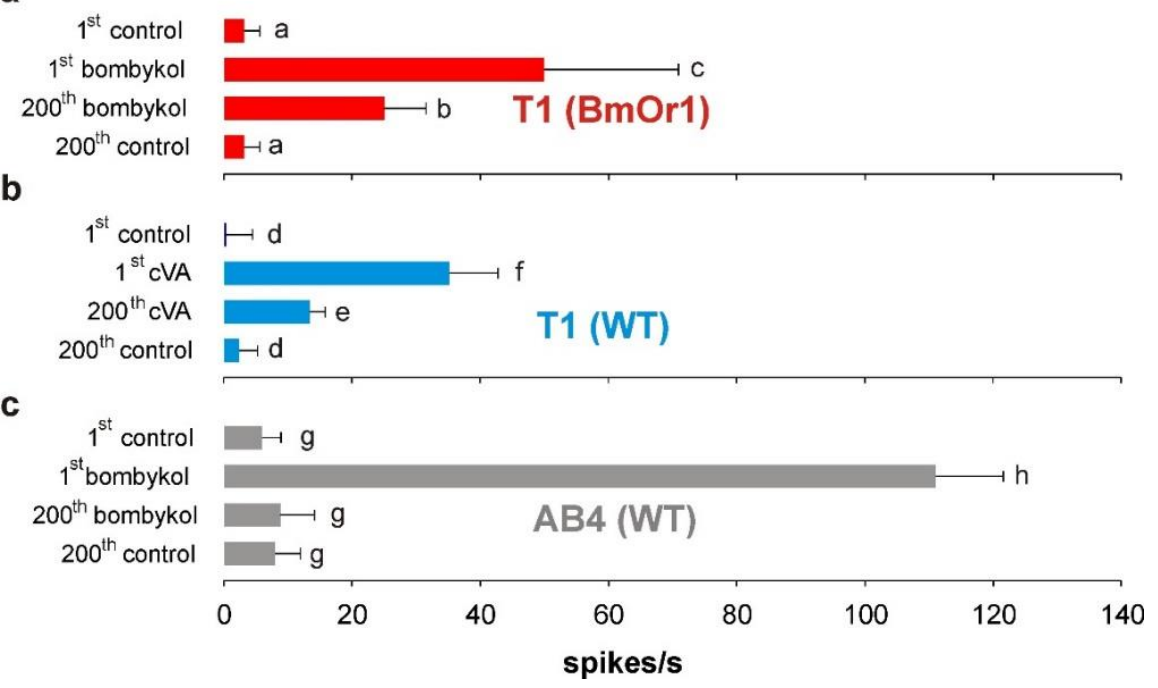

271 Extended Data Figure 1 | Responses (means $+95 \%$ CI) of sensory neurons to stimulation from fresh

272 stimulus cartridges versus cartridges after 200 puffs. While T1 neurons expressing BmOR1 (A) and

273 wild type T1 neurons (B) responded to both fresh $c$ VA-loaded cartridges or cartridges puffed 200 times in

274 succession, AB4a neurons only consistently responded to fresh cartridges (C). Values with the same letters

275 are not significantly different from each other (One Way Repeated Measurements ANOVA, followed by

276 Holm-Sidak multiple comparisons; $\mathrm{p}>0.05, \mathrm{n}=5$ different flies). 
a

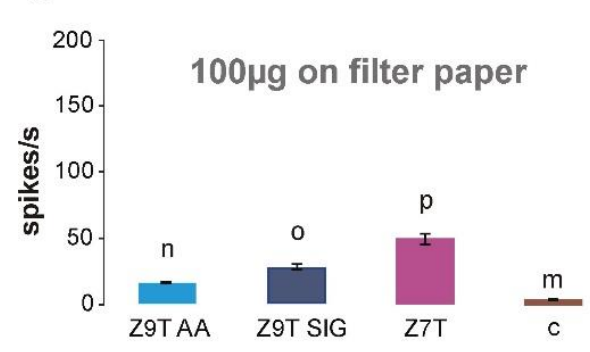

b

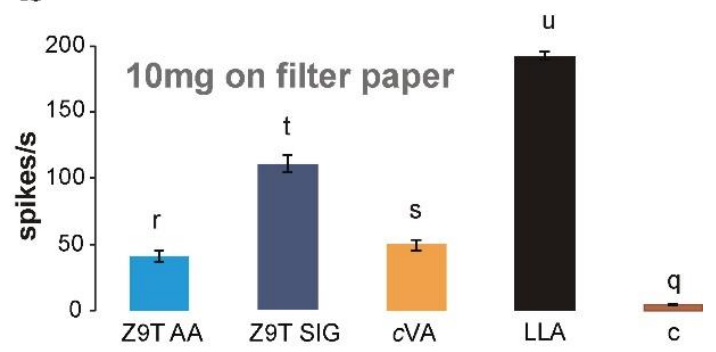

C

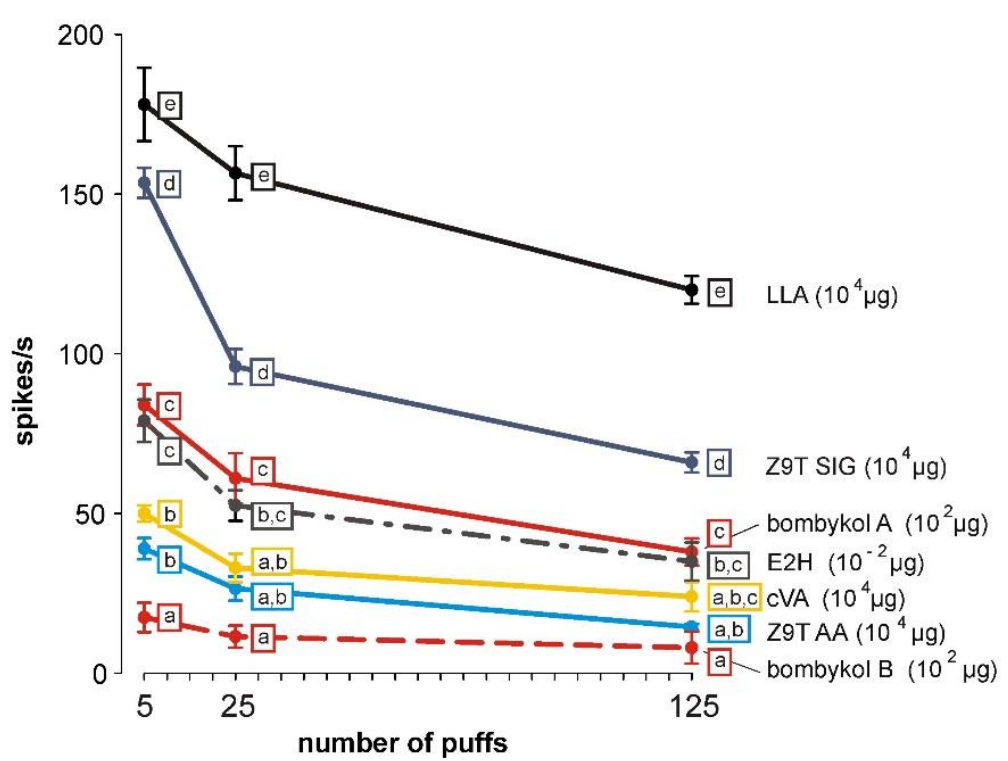

Extended Data Figure 2 | Single sensillum recordings (means \pm SE) from AB4a neurons via puffing using different compounds, batches and depletion series. A, Z9T SIG (100 $\mu \mathrm{g}$ on filter paper) from Sigma-Aldrich induced stronger responses by puffing than Z9T AA from Alfa-Aesar. However, a synthetic sample of $\mathrm{Z7T}$, which is more abundant than $\mathrm{Z9T}$ on D. melanogaster cuticle, induced stronger $\mathrm{AB} 4 \mathrm{a}$ responses ( $\mathrm{n}=7$ flies) than either of the Z9T synthetic samples. B, This also held true at higher doses (10 $\mathrm{mg}$ on filter paper; $\mathrm{n}=7 \mathrm{flies}$ ). At these amounts, even a sample of $\mathrm{cVA}$ induced a response ( $\mathrm{n}=4 \mathrm{flies}$ ). LLA was included as a reference and gave stronger responses ( $n=4$ flies) than Z9T and cVA. C, responses of AB4a neurons ( $\mathrm{n}=4$ flies) to odour cartridges after 5, 25, or 125 repeated stimulations with E2H (10 ng on filter paper) or synthetic bombykol (100 $\mu \mathrm{g}$ on filter paper). Depletion of responses to Z9T (SIG, SigmaAldrich; AA, Alfa Aesar), LLA and cVA standards (10 mg on filter paper) with increasing numbers of puffs are also shown. A new batch of bombykol (dotted red line) induced significantly lower responses from $\mathrm{AB} 4 \mathrm{a}$ neurons compared to a batch (solid red line) received 2 years earlier (see also Extended Data Figure 6). Values with the same letters are not significantly different from each other (One Way Repeated Measurements ANOVA, followed by Holm-Sidak multiple comparisons; p>0.05). 


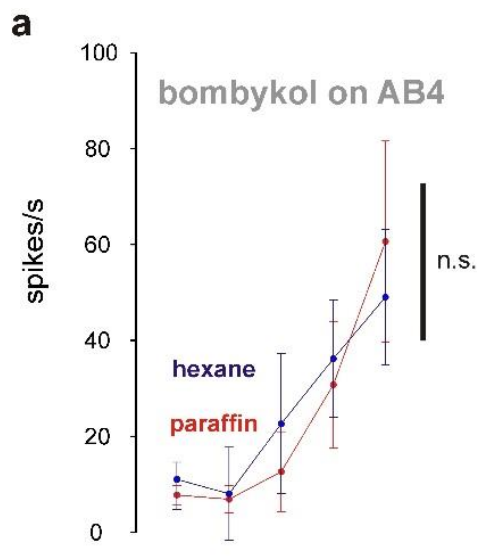

c $10^{-6} 10^{-5} 10^{-4} 10^{-3}$ dilution b

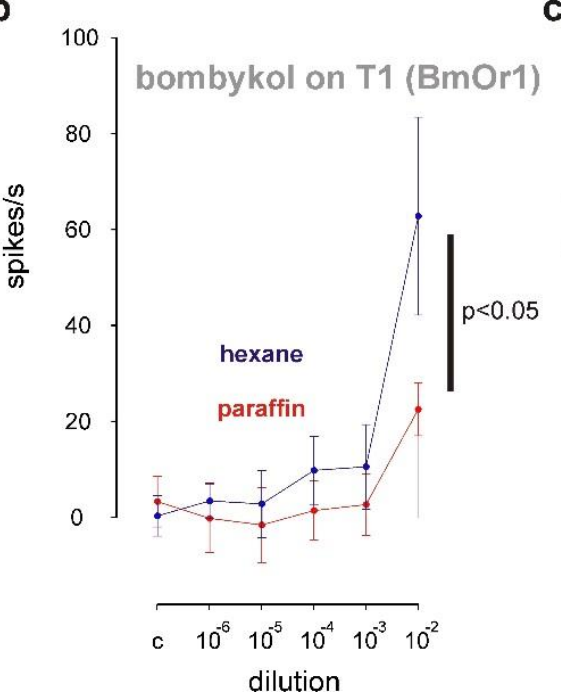

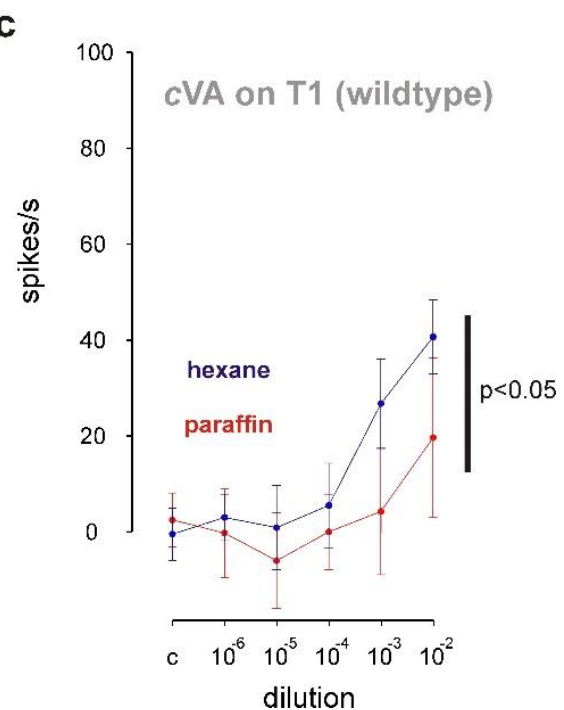

Extended Data Figure 3 | Using paraffin oil as a solvent instead of hexane suppressed the suppress responses in AB4a neurons to the bombykol sample. Dose response curves of AB4a (A) and T1 $(\mathbf{B}, \mathbf{C})$ neurons to bombykol $(\mathbf{A}, \mathbf{B})$ and $c \mathrm{VA}(\mathbf{C})$ diluted in hexane (purple) or paraffin oil (red). Data points represent means $(\mathrm{n}=7(\mathbf{A})$ or $8(\mathbf{B}, \mathbf{C})$ different flies) and their 95\% confidence intervals. Two-way ANOVAs for Repeated Measurements either indicated significant $(\mathrm{p}<0.05$,) or no significant (n.s.; $>0.05)$ differences between hexane and paraffin dilutions. Negative response values resulted when AB4a produced fewer spike/s after stimulation compared to pre-puffing control periods (see methods). 


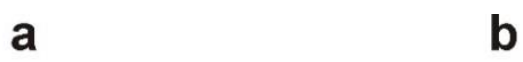

\section{GC eluted compounds}

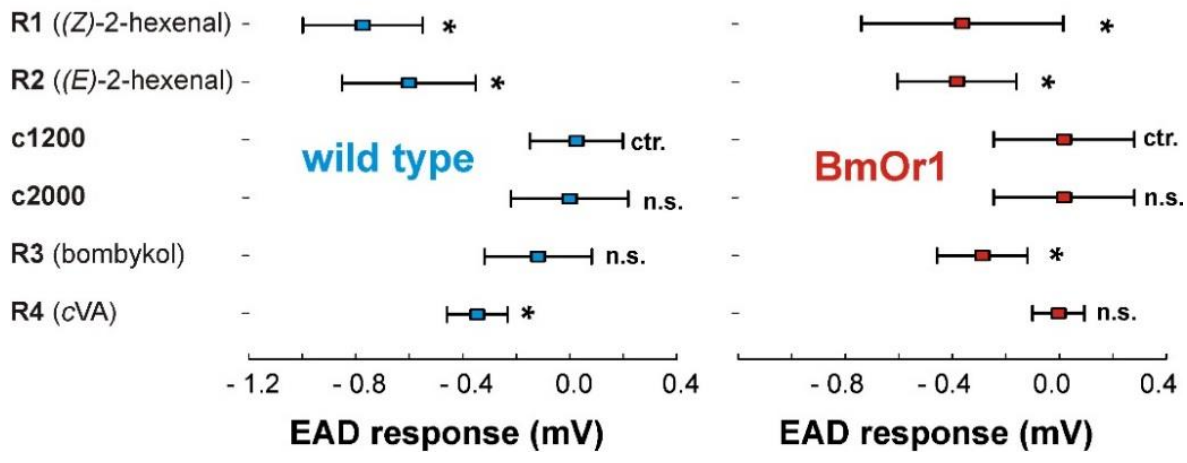
compounds eluting off the GC (see Figure 1) relative to controls. A, Wildtype fly antennae ( $\mathrm{n}=8 \mathrm{flies}$ ), and, B, Fly antennae expressing BmOR1 instead of Or67d in T1 neurons (n=8 flies). Responses (means

$311 \pm 95 \% \mathrm{CI})$ : R1 to (Z)-2-hexenal; R2 to (E)-2-hexenal; R3 to bombykol; R4 to $c \mathrm{VA}$; c1200 and c2000, control

312 responses measured at Kováts Retention Indices 1200 and 2000, respectively. Asterisks (*) indicate 313 significant differences from the control $(\mathrm{p}<0.05$, Holm-Sidak multiple comparisons versus control c1200) 314 following One Way ANOVA analyses ( $\mathrm{n}=2 \mathrm{x} 8$ different flies). n.s. = not significant. 


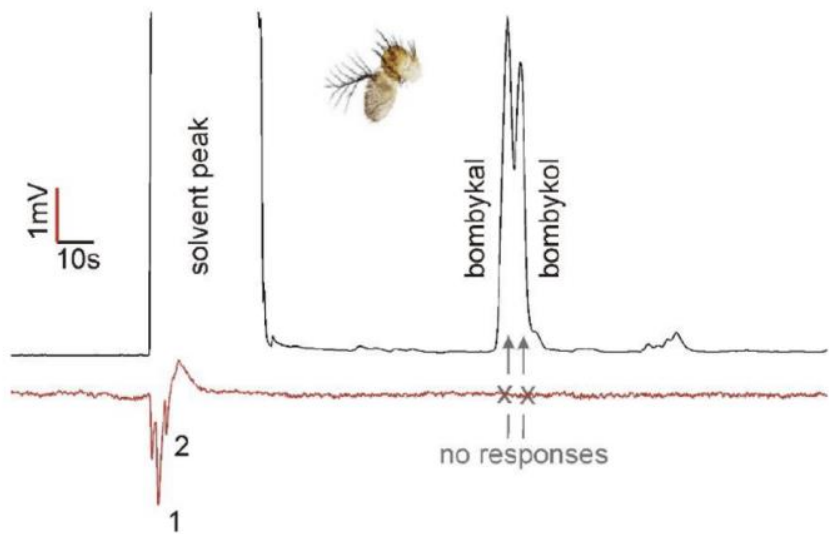

317 Extended Data Figure 5 | Responses of wildtype flies in GC-EAD assays to a blend of bombykol and

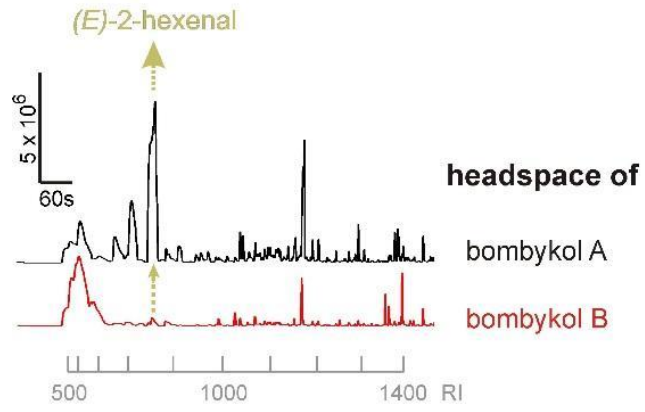

325 Extended Data Figure 6 | SPME analysis showing that the headspace of different batches of synthetic retention index (RI) of 860 . 


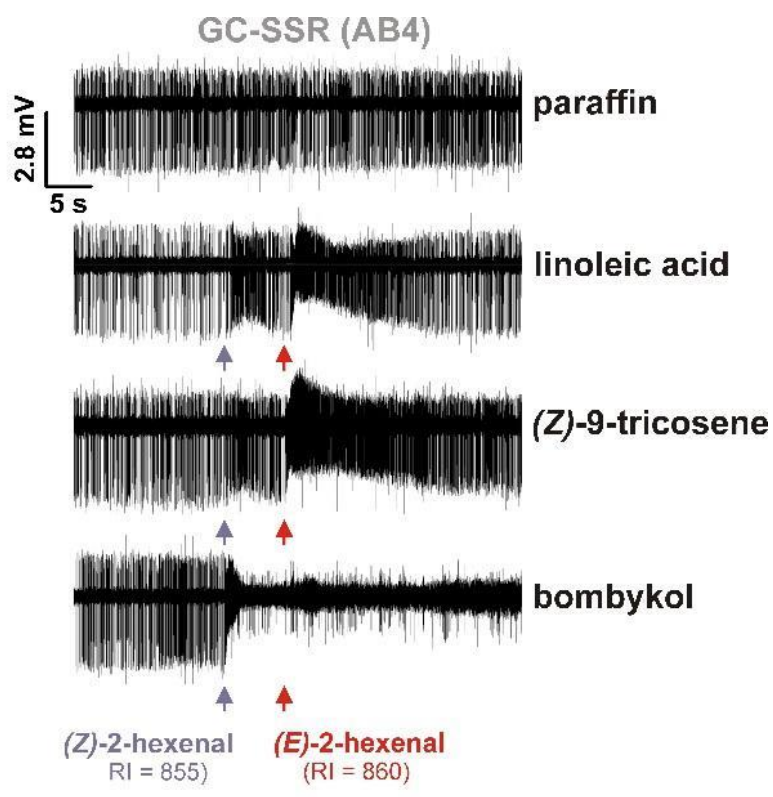

329 Extended Data Figure $7 \mid$ AB4a neurons responded to shared impurities present in the headspace of

330 bombykol, Z9T, and LLA. Aligned segments of GC-SSR traces show that at retention indexes of 885 and

331 860, injected headspace samples (SPME) of bombykol, Z9T, and LLA contain both isomers of 2-hexenal,

332 which, of all compounds in the injected samples, elicited the largest responses from AB4a neurons. 


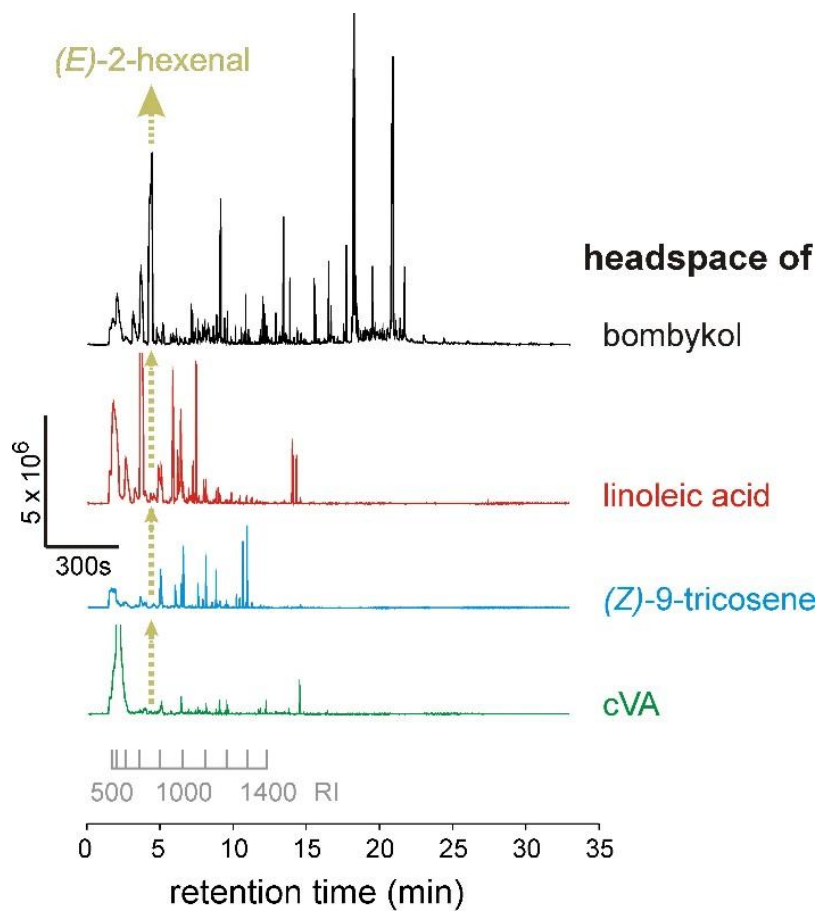

337 Extended Data Figure 8 | SPME profiles from synthetic standards of bombykol, Z9T, and LLA. The

338 various GC traces demonstrate that the amount of E2H differs substantially between these synthetic 339 standards, and correspondingly the responses of $\mathrm{AB} 4 \mathrm{a}$ neurons to these. 


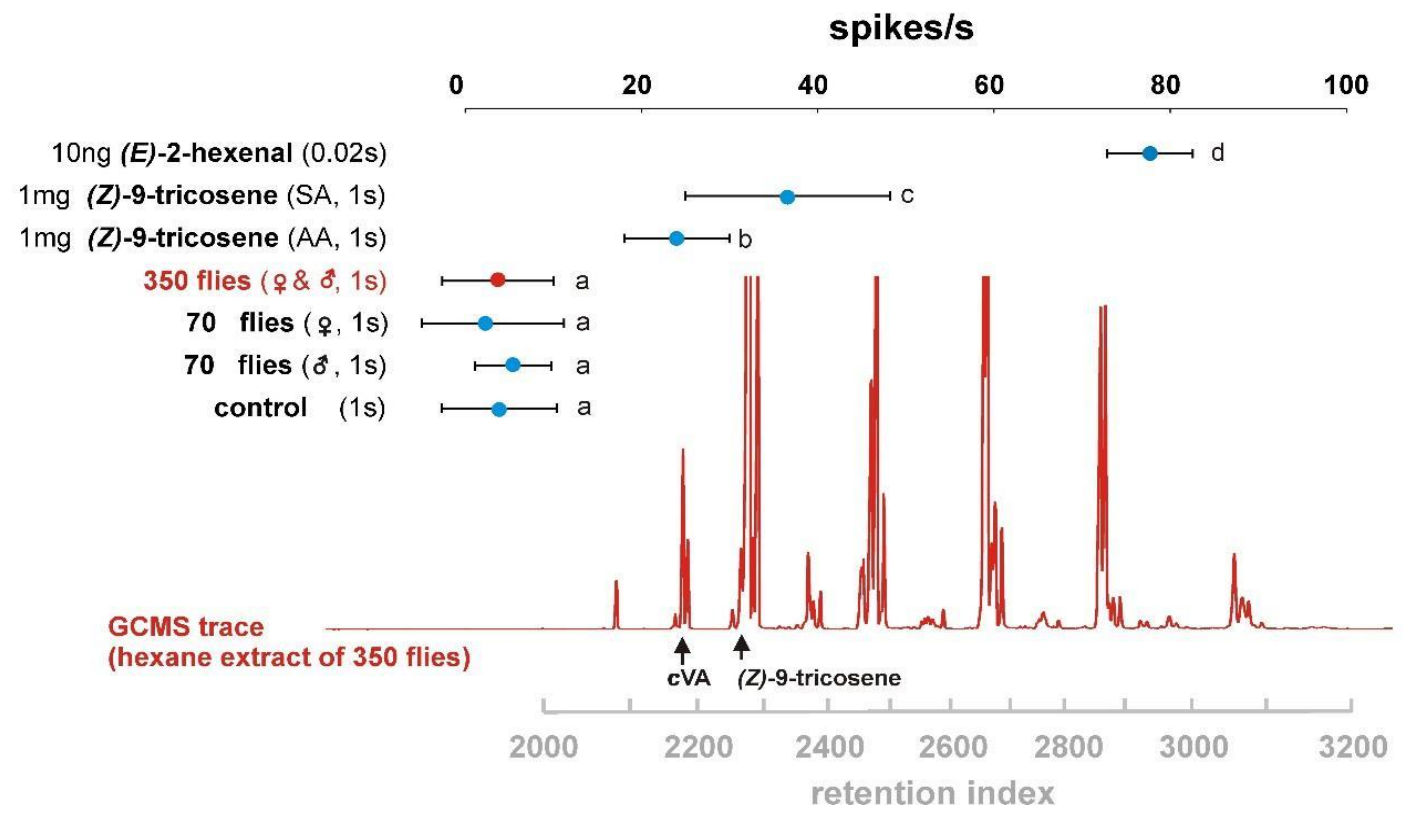

Extended Data Figure 9| GC-MS profile of cuticular extracts of Drosophila and corresponding AB4a 
bioRxiv preprint doi: https://doi.org/10.1101/503169; this version posted December 21, 2018. The copyright holder for this preprint (which was Schorkopf et al. 2018 race impurities can seriously compromise chemosensory studies . No reuse allowed without permission.

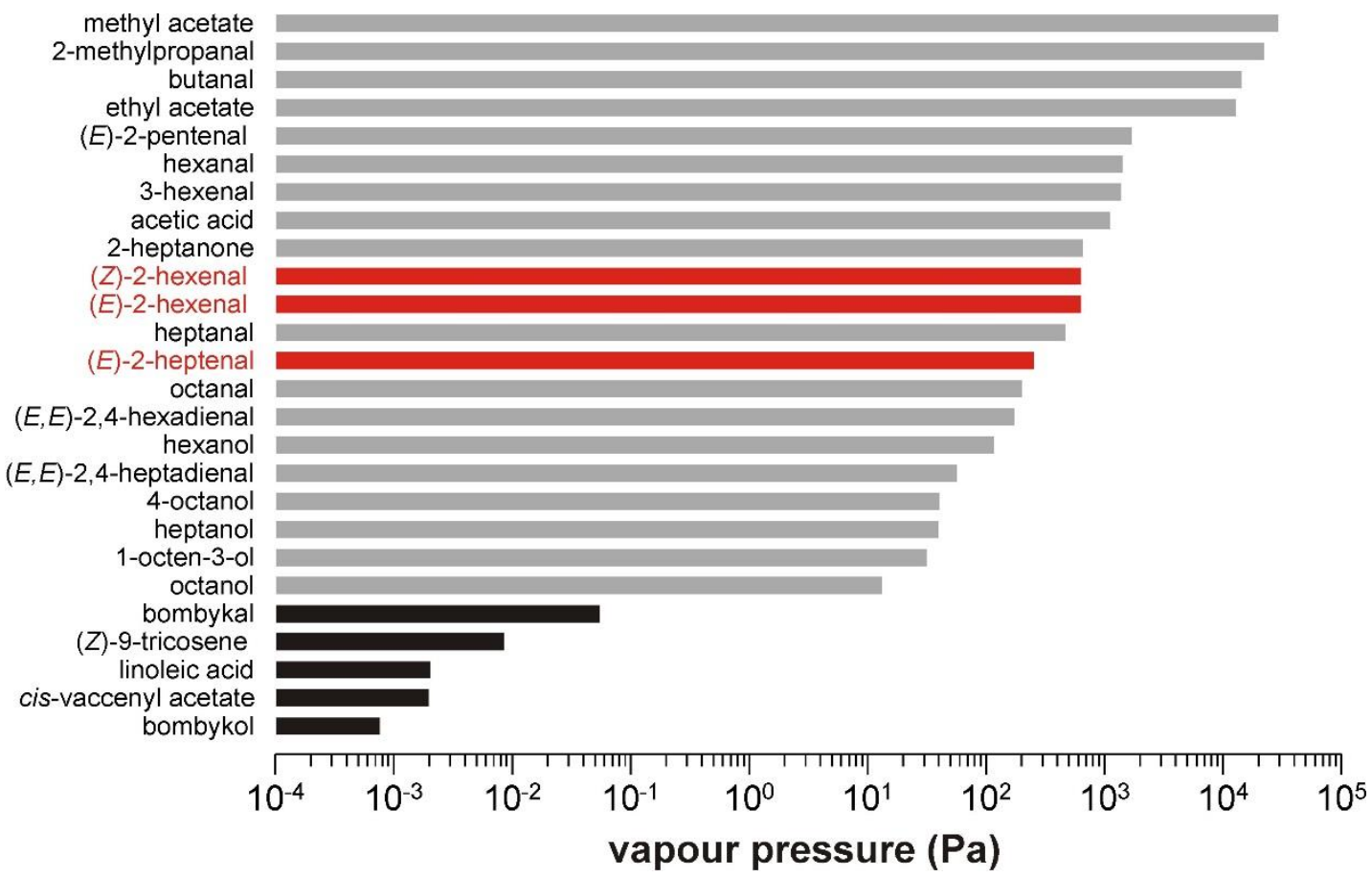

354 Extended Data Figure 10 | Impurities in synthetic compounds can have dramatically higher vapour

355 pressures than the compounds themselves. The bars represent the calculated values of various impurities

356 (see supplementary table 5) arranged in order of decreasing volatility, and presented on a logarithmic scale.

357 Black bars show the values for the compounds studied in the present work. Grey and red bars show the

358 values for those identified impurities that elicited physiological responses. The three physiologically most

359 important impurities with regard to the antennal basiconic 4a neurons of D. melanogaster are shown in red

360 (see also tables 1-3). 


\section{METHODS}

Insects. The wildtype Drosophila melanogaster (Meigen 1830; Diptera, Drosophilidae) were originally collected in 2007 from Dalby, Skåne county, Sweden ${ }^{25}$. Transgenic D. melanogaster expressing Bombyx mori receptor BmOR1 in T1 sensilla were created by crossing OR67d-Gal4 lines (gift from Barry Dickson, Janelia Research Campus, VA, USA) with UAS-BmOR1 (gift from Walter Leal, University of California, Davis CA, USA) to create w;UAS-BmOR1/CyO;OR67d-Gal4/MKRS, which were selected to obtain cornmeal-yeast-agar diet under a $12 \mathrm{~L}: 12 \mathrm{D}$ photoperiod and at $22{ }^{\circ} \mathrm{C}$. and placed in boxes lined with paper until eclosion.

\section{Chemicals and stimuli}

Synthetic compounds were acquired from mostly commercial sources with the highest purity available. (bombykal, purity >95\%), and (Z)-11-octadecenyl acetate (cis-vaccenyl acetate, $c \mathrm{VA}$ ) were obtained from chemicals, including alkane standards for calculation of retention indices (purity $\geq 99 \%$ each), mineral oil

386 (CAS: 8042-47-5), (9Z,12Z)-9,12-octadecadienoic acid (linoleic acid, LLA, purity 99\%) and (E)-2-hexenal 387 (98\% purity) were obtained from Sigma-Aldrich. 

tetrahydrofuran,THF) was added to a slurry of hexadecyltriphenylphosphonium bromide $(3.98 \mathrm{~g}, 7 \mathrm{mmol})$ in THF at $0^{\circ} \mathrm{C}$ under argon until an orange color persisted, followed by addition of another $9.3 \mathrm{ml}(7 \mathrm{mmol})$ of NaHMDS solution. The resulting mixture was stirred $1 \mathrm{~h}$ at $0^{\circ} \mathrm{C}$, then cooled to $-78^{\circ} \mathrm{C}$ in a dry iceacetone bath, and heptanal $(0.74 \mathrm{~g}, 6.5 \mathrm{mmol})$ in $4 \mathrm{ml} \mathrm{THF}$ was added dropwise. The mixture was allowed to warm to room temp over several hours, then quenched with dilute aqueous $\mathrm{NH}_{4} \mathrm{Cl}$, and extracted with hexane. The hexane extract was washed with water and brine, dried over anhydrous $\mathrm{Na}_{2} \mathrm{SO}_{4}$, and concentrated. The residue was triturated with hexane, and the soluble portion was purified by vacuum flash chromatography on silica gel, eluting with hexane. The purified product was then recrystallized from acetone at $-20^{\circ} \mathrm{C}$ overnight, yielding $1.34 \mathrm{~g}$ of a white solid which melted at $\sim 0^{\circ} \mathrm{C}$. The recrystallized product contained about $3 \%$ of the $(E)$-isomer.

For fly extracts, flies were first freeze-killed $\left(\sim 10 \mathrm{~min}\right.$ at $\left.-20^{\circ} \mathrm{C}\right)$ and then placed into a clean 1.5

$\mathrm{ml}$ glass vial to which $3 \mu \mathrm{l}$ of hexane were added per fly (e.g. $1050 \mu \mathrm{l}$ for 350 flies) at room temperature.

The glass was gently shaken for 5 min once a minute and the resulting cuticular extract was transferred to another glass vial. The extract was concentrated by letting the excess hexane evaporate under a gentle control (hexane without flies).

Stimuli were diluted in either $n$-hexane (Merck, purity $\geq 99 \%)$ or in mineral oil, and $10 \mu \mathrm{l}(30 \mu \mathrm{l}$ for fly extracts and their controls) of solutions were applied to filter paper disks (12.7 $\mathrm{mm} \emptyset$; Schleicher 222 \& Schnell GmbH, Dassel, Germany) placed inside Pasteur pipettes. Sodium borohydride (SigmaAldrich, purity $>=96 \%$ ) was used to reduce the aldehydes present in the batches of 2-hexenal and bombykol 410 to the corresponding alcohols (e.g. (E)-2-hexenal to $(E)$-2-hexenol) by adding $25 \mu$ l of a saturated solution 411 of $\mathrm{NaBH}_{4}$ in ethanol ( $\geq 99.9 \%$; Sigma-Aldrich) to $25 \mu \mathrm{l}$ of hexane solutions of either bombykol ( $\left.2 \mathrm{mg}\right)$ or 412 2-hexenal $(4 \mu \mathrm{g})$, respectively, at room temperature. After $5 \mathrm{~min}$, the mixtures were diluted with hexane so 413 as to achieve the desired experimental dilutions (bombykol: $5 \mu \mathrm{g} / \mu \mathrm{l}$; E2H: $10 \mathrm{ng} / \mu \mathrm{l}$ ). We confirmed the 
successful reduction of the aldehydes by GCMS analysis. Controls consisted of hexane solutions of bombykol and 2-hexenal which were treated only with EtOH. For GCMS assisted verification of (Z)-2hexenal a solution of $(Z)$-2-hexenol $(0.1 \mathrm{~g}, 1 \mathrm{mmol})$ in $5 \mathrm{ml} \mathrm{CH}_{2} \mathrm{Cl}_{2}$ was cooled in an icebath, and finely

417 powdered pyridinium dichromate $(0.56 \mathrm{~g}, 1.5 \mathrm{mmol})$ was added in one portion. The mixture was stirred 418 for $2 \mathrm{~h}$ at $0^{\circ} \mathrm{C}$, then diluted with $15 \mathrm{ml}$ ether and filtered through a plug of celite filtering aid. The resulting crude product contained an $\sim 1: 1$ ratio of the $(Z)$ - and $(E)$-isomers, as determined by comparison of the retention time of the second isomer with that of an authentic standard or $(E)$-2-hexenal.

\section{Electrophysiological recordings}

423 For electrophysiological recordings, flies were immobilized in pipette tips with the antennae protruding from the tip. Preparations were placed under a continuous charcoal-filtered, humidified air stream (1 $1 \mathrm{~min}^{-}$

1). Stimuli were injected into this airstream using either a stimulus controller (CS-55, Syntech, Kirchzarten, details, such as stimulus load and duration, are noted in the text and figures.

Headspace collections, gas chromatography (GC), coupled gas chromatography-mass spectrometry (GC-MS) and identifications

436 Headspace volatiles were collected for $20 \mathrm{~min}$ at room temperature using a solid-phase microextraction 437 (SPME, 50/30 $\mu \mathrm{m}$ DVB/CAR/PDMS StableFlex fiber, Supelco/Sigma-Aldrich, Bellefonte, PA) inserted 438 into a $1.5 \mathrm{~mL}$ screwcap vial either empty (control) or loaded with $10 \mu \mathrm{l}$ of the standard being sampled. The 439 fibre was cleaned before use by desorption for $10 \mathrm{~min}$ in a $250^{\circ} \mathrm{C} \mathrm{GC}$ injector port. The pre-sampling 
headspace equilibration time was $10 \mathrm{~min}$. Volatiles collected on the fibre were thermally desorbed directly

441 into the splitless injector of the GC or GC-MS for 0.5 min at $250^{\circ} \mathrm{C}$.

GC, GC-EAD, GC-SSR, and GC-MS usually employed a HP-5 capillary column (GC-EAD: $30 \mathrm{~m}$

$443 \times 0.32 \mathrm{~mm} \times 0.25 \mu \mathrm{m}$ film; GC-MS: 30 (later 60) $\mathrm{m} \times 0.25 \mathrm{~mm} \times 0.25 \mu \mathrm{m}$ film, Agilent Technologies,

444 Santa Clara, CA). For Kováts Index-aided verification of structures we also employed DB-WAX columns

445 (either $30 \mathrm{~m} \times 0.32 \mathrm{~mm} \times 0.25 \mu \mathrm{m}$ film or $60 \mathrm{~m} \times 0.25 \mathrm{~mm} \times 0.25 \mu \mathrm{m}$ film; Agilent) with helium as carrier

446 gas at $1.84 \mathrm{ml} \mathrm{min}^{-1}$. The $\mathrm{HP}-5$ column was used with a temperature program of $50^{\circ} \mathrm{C} / 1 \mathrm{~min}$, then $10^{\circ} \mathrm{C}$

$447 \min ^{-1}$ to $315^{\circ} \mathrm{C}$, hold for $10 \mathrm{~min}$, whereas the DB-WAX column was programmed from either $35^{\circ} \mathrm{C} / 1 \mathrm{~min}$

448 or $30^{\circ} \mathrm{C} / 3 \mathrm{~min}$, then $8^{\circ} \mathrm{C} \mathrm{min}^{-1}$ to $230^{\circ} \mathrm{C}$ for $5 \mathrm{~min}$, unless stated otherwise. For GC-EAD/SSR the effluent

449 was split equally between the flame ionization detector and an antennal preparation, with the portion

450 directed to the antennal preparation exiting via a heated transfer line into a $11 \mathrm{~min}^{-1}$ clean humidified

451 airstream as described above. Electrophysiological and GC signals were integrated using an IDAC-4 A/D

452 converter (Syntech).

Samples were analysed by GC-MS (HP 5890 GC and HP 5975 MS instruments, Agilent) in electron

454 impact ionization mode at $70 \mathrm{eV}$, scanning a mass range of $m / z 29-300$, at 5 scans s$^{-1}$. Single Ion Monitoring

was occasionally employed for trace identification of specific compounds, as specified in the tables.

456 Compounds were tentatively identified by comparison of their mass spectra with mass spectral databases

457 (NIST11 and Wiley) and published Kováts indices, and verified through injection of authentic standards

458 where possible, as specified in the tables.

\section{Vapour pressure calculations}

461 The vapour pressure values were estimated at $25^{\circ} \mathrm{C}$, calculated according to the instructions and methods 462 described in Yaws $(2015)^{18}$. When calculation estimation requirements or missing experimental data did 463 not allow this, estimates were calculated using EPI Suite ${ }^{\mathrm{TM}}$ (v4.11, June 2017), a freely available software 464 developed by the EPA's Office of Pollution Prevention Toxics and Syracuse Research Corporation (SRC

465 Inc.) for the U.S. Environmental Protection Agency. 
Statistical analyses

468 Statistical analyses described in the text and figure legends were performed two-sided using Sigmastat 4.0

469 (Systat Software Inc.), or R 3.2.0 software (R Development Core Team 2015). When the assumptions of 470 normality (Shapiro-Wilk test $\mathrm{p}>0.05$ ) and equal variance (Spearman rank correlation $\mathrm{p}>0.05$ ) were not 471 met, the data (Extended Data Figures 2a, 3b and 3c) were $\ln$-transformed prior to analysis if the 472 assumptions could thus be successfully met.

25. Ruebenbauer, A., Schlyter, F., Hansson, B. S., Löfstedt, C., \& Larsson, M. C. Genetic variability and robustness of host odor preference in Drosophila melanogaster. Curr. Biol., 18 $1438-1443$ (2008).

26. Brand, A. H., \& Perrimon, N. Targeted gene expression as a means of altering cell fates and generating dominant phenotypes. Development, 118, 401-415 (1993).

27. Greenspan, R. J. Fly pushing: the theory and practice of Drosophila genetics. Cold Spring Harbor Laboratory Press, New York (2004).

28. Molnár, B. P., Tóth, Z. \& Zsolt Kárpáti. Synthetic blend of larval frass volatiles repel oviposition in the invasive box tree moth, Cydalima perspectalis. J. Pest Sci. 90, 873-885 (2017). 
Extended Data Table 1 Impurities found in a synthetic standard of bombykol ((10E,12Z)-10,12-hexadecadienol ) by GCMS analysis of headspace volatiles collected by solid phase microextraction. Compounds which were also detected in the control (glass vial without a sample) were excluded if they were not found within treatments in substantially higher amounts (> 200\%). Shown are measured Kováts retention indices (RI), percent relative to the most abundant compound, and percent relative to (E)-2-hexenal in the sample. Only compounds which either elicited a reproducible electrophysiological response, or occurred in amounts greater than 5\% relative to the main compound peak area were included in the table. The asterisk indicates the compound that was mainly responsible for eliciting responses from the $D$. melanogaster $\mathrm{AB} 4 \mathrm{a}$ neuron. Compounds were tentatively identified by matches with NIST database spectra, and where possible, identifications were confirmed by matching retention times and mass spectra with those of authentic standards. Positive GC-EAD and GC-SSR responses are indicated; responses in red were also observed with injected samples of bombykol $(1 \mu \mathrm{g})$. Listed in addition are chemoreceptors reported (DoOR 2.0 database $^{9}$ ) to respond most strongly to a given compound. The reported response level, ranging from 0 (no response) to 1 (max excitation), is indicated within brackets.

\begin{tabular}{|c|c|c|c|c|c|c|c|c|c|c|}
\hline Nr. K & $\begin{array}{c}\text { Kováts } \\
\text { RI }\end{array}$ & $\begin{array}{c}\text { area } \\
\text { rel. } \\
\text { high. peak }\end{array}$ & $\begin{array}{l}\text { area } \\
\text { rel. } \\
\mathrm{E} 2 \mathrm{H}^{*}\end{array}$ & name & CAS & $\begin{array}{c}\text { library } \\
\text { data } \\
\text { match }\end{array}$ & $\begin{array}{c}\text { verified } \\
\text { by } \\
\text { synthetic }\end{array}$ & $\begin{array}{l}\text { EAD } \\
\text { response }\end{array}$ & $\begin{array}{c}\text { SSR } \\
\text { response } \\
\text { (AB4A) }\end{array}$ & $\begin{array}{l}\text { responding } \\
\text { chemoreceptor unit } \\
\left(\text { response level }{ }^{9}\right)\end{array}$ \\
\hline 1 & 606 & $41.55 \%$ & $63.96 \%$ & butanal & $000123-72-8$ & + & & + & & Ir64a.DC4 (0.58); 35a (0.55); 69a (0.34) \\
\hline 2 & 653 & $2.92 \%$ & $4.49 \%$ & 2-butenal $\left.\right|^{1)}$ & 004170-30-3 & + & & & + & \\
\hline 3 & 706 & $8.87 \%$ & $13.65 \%$ & unknown & & & & & & \\
\hline 4 & 749 & $0.63 \%$ & $0.97 \%$ & $(Z)-2$-pentenal $\left.\right|^{2)}$ & 001576-86-9 & & & + & + & \\
\hline 5 & 757 & $19.50 \%$ & $30.02 \%$ & (E)-2-pentenal & 001576-87-0 & + & + & + & + & \\
\hline 6 & 804 & $49.55 \%$ & $76.27 \%$ & 3-hexenal $\left.\right|^{1)}$ & 004440-65-7 & + & + & + & + & \\
\hline 7 & 844 & $12.53 \%$ & $19.28 \%$ & butanoic acid & 000107-92-6 & + & & & & \\
\hline 8 & 855 & $100.00 \%$ & $153.93 \%$ & (Z)-2-hexenal & 016635-54-4 & + & + & + & + & \\
\hline 9 & 862 & $64.96 \%$ & $100.00 \%$ & (E)-2-hexenal* & 006728-26-3 & + & + & + & + & 7a (0.83); ac3B (0.066); 35a (0.66) \\
\hline 10 & 894 & $4.65 \%$ & $7.15 \%$ & unknown & & & & + & & \\
\hline 11 & 902 & $0.25 \%$ & $0.38 \%$ & unknown & & & & + & & \\
\hline 12 & 913 & $7.76 \%$ & $11.94 \%$ & $(E, E)$-2,4-hexadienal ${ }^{3)}$ & 000142-83-6 & + & & + & & \\
\hline 13 & 933 & $0.21 \%$ & $0.32 \%$ & unknown & & & & + & & \\
\hline 14 & 938 & $0.28 \%$ & $0.43 \%$ & unknown & & & & + & & \\
\hline 15 & 960 & $3.26 \%$ & $5.02 \%$ & (E)-2-heptenal & 018829-55-5 & + & + & + & + & ac3B (0.68); \\
\hline 16 & 991 & $1.70 \%$ & $2.62 \%$ & 4-octanol & $000589-62-8$ & + & & + & & 69a (0.65); 13a (0.35) \\
\hline 17 & 1013 & $1.22 \%$ & $1.89 \%$ & $(E, E)-2,4$-heptadienal $\left.\right|^{3)}$ & 004313-03-5 & + & & + & & \\
\hline 18 & 1040 & $6.45 \%$ & $9.92 \%$ & unknown & & & & & & \\
\hline 19 & 1172 & $26.17 \%$ & $40.28 \%$ & unknown & & & & & & \\
\hline 20 & 1174 & $13.60 \%$ & $20.94 \%$ & nonanol & 000143-08-8 & + & & & & \\
\hline 21 & 1259 & $6.84 \%$ & $10.53 \%$ & unknown & & & & & & \\
\hline 22 & 1309 & $5.90 \%$ & $9.07 \%$ & unknown & & & & & & \\
\hline
\end{tabular}


Extended Data Table 2 Impurities found in a synthetic standard of linoleic acid ((9Z,12Z)-9,12octadecadienoic acid) by GCMS analysis of headspace volatiles collected by solid phase microextraction. Compounds which were also detected in the control (glass vial without a sample) were excluded if they were not found within treatments in substantially higher amounts (> 200\%). Shown are measured Kováts retention indices (RI), percent relative to the most abundant compound, and percent relative to (E)-2-hexenal in the bombykol sample (table 1). Only compounds which either elicited a reproducible electrophysiological response, or occurred in amounts greater than 5\% relative to the peak area of the main compound were included in the table. The asterisks indicate the compounds that were mainly responsible for eliciting responses from the $D$. melanogaster AB4a neuron. Compounds were tentatively identified by matches with NIST database spectra, and where possible by comparison with authentic standards. Positive GC-EAD and GC-SSR responses are indicated; responses in red were also observed with injected samples of linoleic acid $(1 \mu \mathrm{g})$. Listed in addition are chemoreceptors reported (DoOR 2.0 database $^{9}$ ) to respond most strongly to a given compound. The reported response level, ranging from 0 (no response) to 1 (max excitation), is indicated within brackets.

\begin{tabular}{|c|c|c|c|c|c|c|c|c|c|c|}
\hline Nr. & $\begin{array}{c}\text { Kováts } \\
\text { RI }\end{array}$ & $\begin{array}{l}\text { area } \\
\text { rel. } \\
\text { high. peak }\end{array}$ & $\begin{array}{l}\text { area } \\
\text { rel. } \\
\mathrm{E} 2 \mathrm{H}^{*}\end{array}$ & name & CAS & $\begin{array}{l}\text { library } \\
\text { data } \\
\text { match }\end{array}$ & $\begin{array}{c}\text { verified } \\
\text { by } \\
\text { synthetic }\end{array}$ & $\begin{array}{c}\text { EAD } \\
\text { response }\end{array}$ & $\begin{array}{c}\text { SSR } \\
\text { response } \\
\text { (AB4A) }\end{array}$ & $\begin{array}{l}\text { responding } \\
\text { chemoreceptor unit } \\
\left(\text { response level }{ }^{9}\right)\end{array}$ \\
\hline 1 & 556 & $33.03 \%$ & $25.58 \%$ & 2-methylpropanal & $000078-84-2$ & + & & + & & \\
\hline 2 & 700 & $25.09 \%$ & $19.43 \%$ & heptane & 000142-82-5 & + & & & & \\
\hline 3 & 752 & $<0.1 \%$ & $<0.1 \%$ & 2-pentenal (traces) $)^{1)}$ & 000764-39-6 & + & & & + & \\
\hline 4 & 806 & $100.00 \%$ & $77.43 \%$ & hexanal & $000066-25-1$ & + & + & + & + & 85b (0.69); ac3B (0.65); 35a (0.56) \\
\hline 5 & 855 & $0.76 \%$ & $0.59 \%$ & (Z)-2-hexenal & 016635-54-4 & + & + & + & + & \\
\hline 6 & 856 & $1.94 \%$ & $1.50 \%$ & (E)-2-hexenal* & $006728-26-3$ & + & + & + & + & 7a (0.83); ac3B (0.066); 35a (0.66) \\
\hline 7 & 870 & $3.15 \%$ & $2.44 \%$ & hexanol & 000111-27-3 & + & & + & & \\
\hline 8 & 894 & $9.16 \%$ & $7.09 \%$ & 2-heptanone & 000124-11-8 & + & + & + & & $85 c(0.65) ; 85 b(0.65) ; 98 a(0.62)$ \\
\hline 9 & 904 & $2.53 \%$ & $1.96 \%$ & heptanal & 000111-71-7 & + & & + & & ас3в (0.59); 22a (0.50); 13a (0.28) \\
\hline 10 & 908 & $7.43 \%$ & $5.76 \%$ & unknown & & & & & & \\
\hline 11 & 929 & $0.67 \%$ & $0.52 \%$ & unknown & & & & + & & \\
\hline 12 & 948 & $0.52 \%$ & $0.41 \%$ & (Z)-2-heptenal & 057266-86-1 & + & & + & + & \\
\hline 13 & 960 & $21.63 \%$ & $16.75 \%$ & (E)-2-heptenal* & 018829-55-5 & + & + & + & + & ac3B (0.68) \\
\hline 14 & 981 & $8.60 \%$ & $6.66 \%$ & 1-octen-3-ol & $003391-86-\triangleleft$ & + & & + & & 13a (0.79); 85c (0.69); 98a (0.58) \\
\hline 15 & 989 & $1.44 \%$ & $1.11 \%$ & unknown & & & & + & & \\
\hline 16 & 994 & $17.54 \%$ & $13.58 \%$ & 2-pentyl furan & 003777-69-3 & + & & & & \\
\hline 17 & 1005 & $2.62 \%$ & $2.03 \%$ & octanal & $000124-13-0$ & + & & + & & 35a (0.48); 69a (0.30); ac3B (0.27) \\
\hline 18 & 1062 & $17.56 \%$ & $13.60 \%$ & 2-octenal ${ }^{1)}$ & 002363-89-5 & + & & & & \\
\hline
\end{tabular}


Extended Data Table 3 Impurities found in a synthetic standard of (Z)-9-tricosene by GCMS analysis of headspace volatiles collected by solid phase microextraction. Compounds which were also detected in the control (glass vial without a sample) were excluded if they were not found within treatments in substantially higher amounts (> 200\%). Shown are measured Kováts retention indices (RI), percent relative to the most abundant compound, and percent relative to $(E)$-2-hexenal in the bombykol sample (Table 1). Only compounds which either elicited a reproducible electrophysiological response, or occurred in amounts greater than $5 \%$ relative to the peak area of the main compound were included in the table. The asterisk indicates the compound that was mainly responsible for eliciting responses from the D. melanogaster $\mathrm{AB} 4$ a neuron. Compounds were tentatively identified by matches with NIST database spectra, and where possible by comparison with authentic standards. Positive GC-EAD and GC-SSR responses are indicated. Listed in addition are chemoreceptors reported (DoOR 2.0 database $^{9}$ ) to respond most strongly to a given compound. The reported response level, ranging from 0 (no response) to 1 (max excitation), is indicated within brackets.

\begin{tabular}{|c|c|c|c|c|c|c|c|c|c|c|}
\hline Nr. & $\begin{array}{c}\text { Kováts } \\
\text { RI }\end{array}$ & $\begin{array}{c}\text { area } \\
\text { rel. } \\
\text { high. peak }\end{array}$ & $\begin{array}{l}\text { area } \\
\text { rel. } \\
\text { E2H* }\end{array}$ & name & CAS & $\begin{array}{c}\text { library } \\
\text { data } \\
\text { match }\end{array}$ & $\begin{array}{c}\text { verified } \\
\text { by } \\
\text { synthetic }\end{array}$ & $\begin{array}{c}\text { EAD } \\
\text { response }\end{array}$ & $\begin{array}{c}\text { SSR } \\
\text { response } \\
\text { (AB4A) }\end{array}$ & $\begin{array}{l}\text { responding } \\
\text { chemoreceptor unit } \\
\left(\text { response level }{ }^{9}\right)\end{array}$ \\
\hline 1 & 574 & $25.84 \%$ & $1.69 \%$ & unknown & & & & & & \\
\hline 2 & 612 & $37.62 \%$ & $2.46 \%$ & acetic acid & 000064-19-7 & + & & + & & Ir64a.DC4 (1.00); ac2 (0.70); Ir75a (0.56) \\
\hline 3 & 678 & $10.31 \%$ & $0.67 \%$ & unknown & & & & & & \\
\hline 4 & 700 & $26.35 \%$ & $1.72 \%$ & heptane & $000142-82-5$ & + & & & & \\
\hline 5 & 774 & $9.06 \%$ & $0.59 \%$ & unknown & & & & & & \\
\hline 6 & 806 & $41.02 \%$ & $2.68 \%$ & hexanal & $000066-25-1$ & + & & + & & 85b (0.69); ac3B (0.65); 35a (0.56) \\
\hline 7 & 850 & traces & traces & (Z)-2-hexenal & $016635-54-4$ & + & + & + & + & \\
\hline 8 & 858 & traces & traces & (E)-2-hexenal* & $006728-26-3$ & + & + & + & + & 7a (0.83); ac3B (0.066); 35a (0.66) \\
\hline 9 & 867 & $5.90 \%$ & $0.39 \%$ & hexanol & $000111-27-3$ & + & & + & & $67 \mathrm{~b}(0.74) ;$ ac3B (0.72); 35a (0.71) \\
\hline 10 & 890 & $1.74 \%$ & $0.11 \%$ & 2-heptanone & $000110-43-0$ & + & & + & & $85 c(0.65) ; 85 b(0.65) ; 98 a(0.62)$ \\
\hline 11 & 901 & $98.60 \%$ & $6.44 \%$ & heptanal & $000111-71-7$ & + & & + & & ac3B (0.59); 22a (0.50); 13a (0.28) \\
\hline 12 & 956 & $1.63 \%$ & $0.11 \%$ & (E)-2-heptenal & $002463-63-0$ & + & + & + & & ac3B (0.68) \\
\hline 13 & 968 & $45.96 \%$ & $3.00 \%$ & heptanol & $000111-70-6$ & + & & + & & 35a (0.73); 85c (0.73); 67b (0.55) \\
\hline 14 & 980 & $1.89 \%$ & $0.12 \%$ & unknown & & & & + & & \\
\hline 15 & 1004 & $100.00 \%$ & $6.53 \%$ & octanal & $000124-13-1$ & + & & + & & 35a (0.48); 69a (0.30); ac3B (0.27) \\
\hline 16 & 1070 & $31.05 \%$ & $2.03 \%$ & octanol & 000111-87-! & + & & + & & ac3B (0.68); 35a (0.67); 19a (0.22) \\
\hline 17 & 1093 & $7.67 \%$ & $0.50 \%$ & 2-nonanone & $000821-55-6$ & + & & & & \\
\hline 18 & 1106 & $42.01 \%$ & $2.74 \%$ & nonanal & 000124-19-6 & + & & & & \\
\hline 19 & 1170 & $10.86 \%$ & $0.71 \%$ & octanoic acid & $000124-07-2$ & + & & & & \\
\hline 20 & 1300 & $54.11 \%$ & $3.54 \%$ & tridecane & 000629-50-5 & + & & & & \\
\hline
\end{tabular}


Extended Data Table 4 Impurities found in a synthetic standard of cis-vaccenyl acetate (cVA) by GCMS analysis of headspace volatiles collected by solid phase microextraction. Compounds which were also detected in the control (glass vial without a sample) were excluded if they were not found within treatments in substantially higher amounts (> 200\%). Shown are measured Kováts retention indices (RI), percent relative to the most abundant compound, and percent relative to (E)-2-hexenal in the bombykol sample (Table 1). Only compounds which either elicited a reproducible electrophysiological response, or occurred in amounts greater than 5\% relative to the peak area of the main compound were included in the table. The asterisks indicate the volatiles that were mainly responsible for eliciting responses from the D. melanogaster antenna. Compounds were tentatively identified by matches with NIST database spectra, and where possible by comparison with authentic standards. Positive GC-EAD responses are indicated. Listed in addition are chemoreceptors reported (DoOR 2.0 database $^{9}$ ) to respond most strongly to a given compound. The reported response level, ranging from 0 (no response) to 1 (max excitation), is indicated within brackets.

\begin{tabular}{|c|c|c|c|c|c|c|c|c|c|}
\hline $\mathrm{Nr}$. & $\begin{array}{c}\text { Kováts } \\
\text { RI }\end{array}$ & $\begin{array}{c}\text { area } \\
\text { rel. } \\
\text { high. peak }\end{array}$ & $\begin{array}{l}\text { area } \\
\text { rel. } \\
\text { E2H* }\end{array}$ & name & CAS & $\begin{array}{c}\text { library } \\
\text { data } \\
\text { match }\end{array}$ & $\begin{array}{c}\text { verified } \\
\text { by } \\
\text { synthetic }\end{array}$ & $\begin{array}{c}\text { EAD } \\
\text { response }\end{array}$ & $\begin{array}{l}\text { responding } \\
\text { chemoreceptor unit } \\
\left(\text { response level }^{9}\right)\end{array}$ \\
\hline 1 & 503 & $10.74 \%$ & $6.39 \%$ & acetone & $000067-64-1$ & + & & & \\
\hline 2 & 542 & traces & traces & methyl acetate & $000079-20-9$ & + & & + & 59b (0.74); 42a (0.61); 42b (0.52) \\
\hline 3 & 600 & $29.35 \%$ & $17.47 \%$ & hexane & $000110-54-3$ & + & + & & \\
\hline 4 & 615 & $4.12 \%$ & $2.45 \%$ & ethyl acetate* & $000141-78-6$ & + & + & + & 42a (0.72); 42b (0.61); 59b (0.58) \\
\hline 5 & 618 & $100.00 \%$ & $59.53 \%$ & acetic acid & $000064-19-7$ & + & & $(+)^{\S}$ & Ir64a.DC4 (1.00); ac2 (0.70); Ir75a (0.56) \\
\hline 6 & 655 & $10.96 \%$ & $6.52 \%$ & methyl cyclopentane & 000096-37-7 & + & & & \\
\hline 7 & 676 & $6.02 \%$ & $3.59 \%$ & cyclohexane & $000110-82-7$ & + & & & \\
\hline 8 & 755 & $0.21 \%$ & $0.12 \%$ & unknown & & & & + & \\
\hline 9 & 802 & $0.76 \%$ & $0.45 \%$ & hexanal & $000066-25-1$ & + & + & + & 85b (0.69); ac3B (0.65); 35a (0.56) \\
\hline 10 & 850 & $0.58 \%$ & $0.34 \%$ & (Z)-2-hexenal & $016635-54-4$ & + & + & + & \\
\hline 11 & 854 & $1.19 \%$ & $0.71 \%$ & (E)-2-hexenal* & 006728-26-3 & + & + & + & 7a (0.83); ас3в (0.066); 35a (0.66) \\
\hline
\end{tabular}

${ }^{\S}(+)$ in brackets because acetic acid coelutes together with several other minor compounds on HP5 columns 
Supplementary Table 1 Mass to charge number of bombykol impurities listed in Extended Data Table 1. For each compound, the Kováts retention index (RI) and the fifteen most abundant fragments by their mass to charge numbers are given, followed by each fragment's abundance relative to the base peak at $100 \%$ abundance.

\begin{tabular}{|c|c|c|c|c|c|c|c|c|c|c|c|c|c|c|c|c|c|c|}
\hline \multirow[b]{2}{*}{ nr. } & \multirow[b]{2}{*}{ name } & \multirow[b]{2}{*}{ Kováts RI } & & \multicolumn{15}{|c|}{ most abundant fragments } \\
\hline & & & & 1 & 2 & 3 & 4 & 5 & 6 & 7 & 8 & 9 & 10 & 11 & 12 & 13 & 14 & 15 \\
\hline \multirow[t]{2}{*}{1} & butanal & 606 & $\mathrm{~m} / \mathbf{z}$ & 44.1 & 72.1 & 43.2 & 41.2 & 29.2 & 57.1 & 39.1 & 42.1 & 31.1 & 71.1 & 45.1 & 38.1 & 60.1 & 40.2 & 73.1 \\
\hline & & & rel. abund. & 100.0 & 93.9 & 93.5 & 74.8 & 53.8 & 36.7 & 34.4 & 19.0 & 16.2 & 9.5 & 8.0 & 6.7 & 5.1 & 4.8 & 4.6 \\
\hline \multirow[t]{2}{*}{2} & 2-butenal & 653 & $\mathbf{m} / \mathbf{z}$ & 70.1 & 41.2 & 39.1 & 69.1 & 42.1 & 43.1 & 29.1 & 38.1 & 40.1 & 32.1 & 37.1 & 71.1 & 55.1 & 45.1 & 50.1 \\
\hline & & & rel. abund. & 100.0 & 73.4 & 56.0 & 47.1 & 15.4 & 11.9 & 10.5 & 10.4 & 9.9 & 8.5 & 6.5 & 5.2 & 3.5 & 3.1 & 2.9 \\
\hline \multirow[t]{2}{*}{3} & unknown & 706 & $\mathrm{~m} / \mathrm{z}$ & 43.1 & 81.1 & 55.1 & 77.1 & 29.2 & 41.2 & 71.1 & 74.1 & 57.1 & 73.1 & 56.1 & 45.1 & 96.1 & 84.1 & 39.1 \\
\hline & & & rel. abund. & 100.0 & 89.2 & 77.4 & 70.9 & 68.6 & 68.0 & 63.3 & 61.4 & 57.3 & 41.5 & 41.4 & 41.1 & 37.5 & 37.3 & 36.8 \\
\hline \multirow[t]{2}{*}{4} & (Z)-2-pentenal & 749 & $\mathrm{~m} / \mathrm{z}$ & 55.1 & 83.1 & 84.1 & 29.2 & 39.1 & 41.1 & 56.1 & 32.1 & 53.2 & 69.1 & 57.1 & 44.1 & 40.1 & 43.1 & 45.2 \\
\hline & & & rel. abund. & 100.0 & 87.7 & 87.7 & 51.1 & 42.4 & 33.2 & 29.2 & 26.5 & 19.9 & 15.4 & 11.7 & 10.8 & 10.4 & 10.0 & 9.9 \\
\hline \multirow[t]{2}{*}{5} & (E)-2-pent enal & 757 & $\mathrm{~m} / \mathbf{z}$ & 55.1 & 83.1 & 84.1 & 39.1 & 41.2 & 29.2 & 53.1 & 56.1 & 69.1 & 50.1 & 51.1 & 57.1 & 40.1 & 38.1 & 66.1 \\
\hline & & & rel. abund. & 100.0 & 80.5 & 65.4 & 38.1 & 35.8 & 31.6 & 18.6 & 18.1 & 11.4 & 8.3 & 7.9 & 7.0 & 5.9 & 5.8 & 5.0 \\
\hline \multirow[t]{2}{*}{6} & 3-hexenal & 804 & $\mathrm{~m} / \mathrm{z}$ & 41.2 & 69.1 & 55.2 & 39.2 & 80.1 & 83.1 & 42.2 & 70.1 & 29.2 & 98.1 & 53.1 & 43.1 & 56.1 & 67.2 & 54.2 \\
\hline & & & rel. abund. & 100.0 & 62.7 & 34.3 & 30.4 & 20.1 & 17.9 & 17.6 & 17.6 & 13.9 & 11.8 & 11.6 & 10.6 & 7.3 & 7.2 & 5.2 \\
\hline \multirow[t]{2}{*}{7} & butanoic acid & 844 & $\mathrm{~m} / \mathrm{z}$ & 60.1 & 73.1 & 42.1 & 41.2 & 45.1 & 43.1 & 39.1 & 55.1 & 29.2 & 71.1 & 88.1 & 61.1 & 87.1 & 38.1 & 69.1 \\
\hline & & & rel. abund. & 100.0 & 36.7 & 16.6 & 15.6 & 13.1 & 12.9 & 9.7 & 8.1 & 6.5 & 2.6 & 2.6 & 2.4 & 1.9 & 1.9 & 1.8 \\
\hline \multirow[t]{2}{*}{8} & (Z)-2-hexenal & 855 & $\mathrm{~m} / \mathrm{z}$ & 83.1 & 55.2 & 69.1 & 41.2 & 39.2 & 42.2 & 70.1 & 29.2 & 56.1 & 97.1 & 57.1 & 43.1 & 79.1 & 53.2 & 98.2 \\
\hline & & & rel. abund. & 100.0 & 72.1 & 56.4 & 53.3 & 45.2 & 24.0 & 21.4 & 19.6 & 18.0 & 16.7 & 14.9 & 14.8 & 13.8 & 13.3 & 11.8 \\
\hline \multirow[t]{2}{*}{9} & (E)-2-hexenal & 862 & $\mathrm{~m} / \mathbf{z}$ & 55.2 & 41.2 & 69.2 & 83.1 & 39.2 & 42.2 & 57.1 & 29.2 & 98.2 & 70.1 & 97.2 & 43.2 & 56.2 & 80.1 & 53.2 \\
\hline & & & rel. abund. & 100.0 & 96.7 & 96.5 & 94.0 & 69.5 & 53.5 & 49.1 & 32.3 & 30.0 & 28.8 & 21.9 & 18.8 & 18.8 & 18.3 & 16.2 \\
\hline \multirow[t]{2}{*}{10} & unknown & 894 & $\mathrm{~m} / \mathrm{z}$ & 71.1 & 41.2 & 60.1 & 55.1 & 29.2 & 73.1 & 43.1 & 39.1 & 56.1 & 57.1 & 107.1 & 42.1 & 72.1 & 101.1 & 44.1 \\
\hline & & & rel. abund. & 100.0 & 30.5 & 24.7 & 24.4 & 21.1 & 19.9 & 13.6 & 12.5 & 12.4 & 9.5 & 7.9 & 5.6 & 4.5 & 4.4 & 4.3 \\
\hline 11 & unknown & 902 & $\mathrm{~m} / \mathrm{z}$ & 133.1 & 151.1 & 81.1 & 71.1 & 43.1 & 41.2 & 55.1 & 89.1 & 39.1 & 135.1 & 57.1 & 32.1 & 29.1 & 42.2 & 53.1 \\
\hline
\end{tabular}


Supplementary Table 1 (continued)

\begin{tabular}{|c|c|c|c|c|c|c|c|c|c|c|c|c|c|c|c|c|c|c|}
\hline \multirow[b]{2}{*}{ nr. } & \multirow[b]{2}{*}{ name } & \multirow[b]{2}{*}{ Kováts RI } & & \multicolumn{15}{|c|}{ most abundant fragments } \\
\hline & & & & 1 & 2 & 3 & 4 & 5 & 6 & 7 & 8 & 9 & 10 & 11 & 12 & 13 & 14 & 15 \\
\hline \multirow[t]{2}{*}{12} & $(E, E)-2,4$-hexadienal & 913 & $\mathbf{m} / \mathbf{z}$ & 81.1 & 96.1 & 67.1 & 39.1 & 53.1 & 41.2 & 95.1 & 65.1 & 40.1 & 82.1 & 66.1 & 51.1 & 68.1 & 38.1 & 63.1 \\
\hline & & & rel. abund. & 100.0 & 38.3 & 26.5 & 25.8 & 22.8 & 21.9 & 13.9 & 12.5 & 6.6 & 5.4 & 4.8 & 4.8 & 4.5 & 4.5 & 3.9 \\
\hline \multirow[t]{2}{*}{13} & unknown & 933 & $\mathrm{~m} / \mathbf{z}$ & 55.1 & 41.1 & 43.1 & 32.1 & 97.2 & 29.2 & 39.2 & 56.1 & 83.1 & 69.1 & 71.1 & 112.1 & 73.1 & 42.2 & 45.1 \\
\hline & & & rel. abund. & 100.0 & 78.8 & 49.0 & 47.7 & 40.0 & 40.0 & 38.5 & 30.8 & 26.4 & 24.1 & 23.8 & 21.0 & 18.5 & 17.7 & 17.0 \\
\hline \multirow[t]{2}{*}{14} & unknown & 938 & $\mathbf{m} / \mathbf{z}$ & 55.1 & 97.1 & 83.1 & 43.1 & 41.2 & 69.2 & 39.1 & 32.1 & 112.1 & 29.2 & 98.1 & 68.1 & 42.1 & 53.1 & 57.1 \\
\hline & & & rel. abund. & 100.0 & 65.9 & 41.1 & 40.8 & 38.3 & 27.7 & 26.9 & 24.7 & 17.1 & 16.6 & 15.5 & 13.9 & 13.8 & 11.5 & 11.4 \\
\hline \multirow[t]{2}{*}{15} & (E)-2-heptenal & 960 & $\mathbf{m} / \mathbf{z}$ & 83.1 & 57.1 & 41.1 & 55.1 & 56.1 & 70.1 & 69.1 & 29.2 & 39.1 & 68.1 & 85.1 & 43.1 & 84.1 & 86.2 & 42.2 \\
\hline & & & rel. abund. & 100.0 & 91.1 & 81.6 & 75.3 & 51.8 & 45.1 & 44.6 & 42.5 & 41.6 & 39.9 & 34.3 & 34.3 & 23.6 & 22.7 & 21.8 \\
\hline \multirow[t]{2}{*}{16} & 4-octanol & 991 & $\mathrm{~m} / \mathrm{z}$ & 69.1 & 55.1 & 73.1 & 87.2 & 41.2 & 43.2 & 57.1 & 29.2 & 45.1 & 70.2 & 44.1 & 39.2 & 72.1 & 31.1 & 56.1 \\
\hline & & & rel. abund. & 100.0 & 82.9 & 77.9 & 52.6 & 31.9 & 30.5 & 16.3 & 11.9 & 9.5 & 8.9 & 8.1 & 7.7 & 7.5 & 7.5 & 6.6 \\
\hline \multirow[t]{2}{*}{17} & $(E, E)-2,4$-heptadienal & 1013 & $\mathrm{~m} / \mathbf{z}$ & 81.1 & 110.1 & 53.1 & 39.2 & 41.2 & 79.1 & 67.2 & 68.1 & 82.1 & 77.1 & 55.1 & 65.1 & 51.1 & 95.1 & 29.1 \\
\hline & & & rel. abund. & 100.0 & 17.9 & 15.9 & 13.7 & 13.4 & 11.3 & 10.2 & 8.3 & 7.0 & 6.2 & 6.1 & 5.9 & 4.9 & 4.6 & 4.3 \\
\hline \multirow[t]{2}{*}{18} & unknown & 1040 & $\mathbf{m} / \mathbf{z}$ & 83.1 & 85.1 & 55.1 & 84.1 & 57.1 & 29.2 & 67.1 & 112.1 & 41.2 & 43.1 & 39.1 & 54.1 & 56.1 & 53.1 & 86.1 \\
\hline & & & rel. abund. & 100.0 & 42.1 & 25.6 & 24.1 & 16.3 & 9.6 & 8.8 & 7.9 & 7.5 & 7.2 & 5.4 & 4.5 & 3.6 & 2.7 & 2.2 \\
\hline \multirow[t]{2}{*}{19} & unknown & 1172 & $\mathbf{m} / \mathbf{z}$ & 67.2 & 81.2 & 95.2 & 55.2 & 41.2 & 54.2 & 82.2 & 68.2 & 96.2 & 57.1 & 69.2 & 39.2 & 79.1 & 53.2 & 124.2 \\
\hline & & & rel. abund. & 100.0 & 90.9 & 71.1 & 65.8 & 57.3 & 56.2 & 55.3 & 52.1 & 42.2 & 26.7 & 22.0 & 21.4 & 16.0 & 15.6 & 15.1 \\
\hline \multirow[t]{2}{*}{20} & nonanol & 1174 & $\mathrm{~m} / \mathbf{z}$ & 56.2 & 55.2 & 70.2 & 69.2 & 41.2 & 43.2 & 83.2 & 97.2 & 98.2 & 57.2 & 84.2 & 42.2 & 68.2 & 29.2 & 31.2 \\
\hline & & & rel. abund. & 100.0 & 91.8 & 88.8 & 77.7 & 66.2 & 58.3 & 48.3 & 40.0 & 36.7 & 35.7 & 33.0 & 29.1 & 27.0 & 19.9 & 17.3 \\
\hline \multirow[t]{2}{*}{21} & unknown & 1259 & $\mathrm{~m} / \mathrm{z}$ & 55.2 & 69.2 & 83.2 & 70.2 & 56.2 & 41.2 & 57.2 & 97.2 & 182.3 & 43.2 & 84.2 & 67.2 & 71.2 & 111.2 & 98.2 \\
\hline & & & rel. abund. & 100.0 & 84.4 & 68.0 & 65.7 & 62.3 & 61.6 & 49.7 & 47.6 & 42.5 & 39.5 & 36.3 & 20.6 & 20.5 & 20.5 & 18.0 \\
\hline \multirow[t]{2}{*}{22} & unknown & 1309 & $m / z$ & 67.1 & 55.2 & 81.1 & 97.1 & 79.1 & 84.1 & 95.1 & 69.1 & 41.2 & 54.1 & 43.2 & 93.1 & 68.1 & 83.1 & 82.2 \\
\hline & & & rel. abund. & 100.0 & 98.1 & 91.1 & 78.7 & 75.7 & 71.4 & 71.0 & 70.7 & 69.6 & 57.6 & 56.3 & 47.7 & 41.0 & 40.7 & 39.0 \\
\hline
\end{tabular}


Supplementary Table 2 Mass to charge ratios of ions from linoleic acid impurities listed in Extended Data Table 2. For each compound, the Kováts retention index (RI) and the fifteen most abundant fragments by their mass to charge numbers are given, followed by each fragment's abundance relative to the base peak at $100 \%$ abundance.

\begin{tabular}{|c|c|c|c|c|c|c|c|c|c|c|c|c|c|c|c|c|c|c|}
\hline \multirow[b]{2}{*}{ nr. } & \multirow[b]{2}{*}{ name } & \multirow[b]{2}{*}{ Kováts RI } & & \multicolumn{15}{|c|}{ most abundant fragments } \\
\hline & & & & 1 & 2 & 3 & 4 & 5 & 6 & 7 & 8 & 9 & 10 & 11 & 12 & 13 & 14 & 15 \\
\hline \multirow[t]{2}{*}{1} & 2-methylpropanal & 556 & $\mathbf{m} / \mathbf{z}$ & 43.2 & 42.2 & 41.2 & 32.1 & 57.2 & 39.2 & 72.2 & 55.2 & 40.1 & 56.2 & 58.2 & 53.1 & 38.2 & 47.1 & 51.1 \\
\hline & & & rel. abund. & 100.0 & 56.9 & 55.2 & 36.6 & 19.3 & 19.0 & 16.2 & 7.6 & 7.0 & 6.0 & 3.3 & 2.5 & 2.3 & 1.9 & 1.7 \\
\hline \multirow[t]{2}{*}{2} & heptane & 700 & $\mathrm{~m} / \mathbf{z}$ & 43.2 & 41.2 & 57.1 & 71.2 & 29.2 & 56.2 & 39.2 & 42.2 & 70.2 & 77.1 & 55.1 & 100.2 & 45.1 & 78.1 & 86.1 \\
\hline & & & rel. abund. & 100.0 & 84.1 & 81.6 & 57.8 & 57.0 & 33.2 & 30.3 & 30.1 & 26.9 & 25.0 & 21.3 & 19.9 & 17.4 & 4.9 & 4.1 \\
\hline \multirow[t]{2}{*}{3} & 2-pentenal (traces) & 752 & $\mathbf{m} / \mathbf{z}$ & 55.1 & 83.1 & 84.1 & 41.2 & 29.2 & 56.2 & 39.1 & 67.1 & 57.1 & 53.1 & 44.0 & 96.1 & 54.1 & 77.1 & 69.1 \\
\hline & & & rel. abund. & 100.0 & 67.5 & 64.8 & 58.0 & 49.4 & 43.8 & 43.2 & 38.5 & 30.1 & 29.6 & 27.2 & 24.1 & 23.1 & 22.0 & 21.6 \\
\hline \multirow[t]{2}{*}{4} & hexanal & 806 & $\mathrm{~m} / \mathbf{z}$ & 56.2 & 41.2 & 44.2 & 57.2 & 43.2 & 29.2 & 39.2 & 72.1 & 82.1 & 55.2 & 71.2 & 67.2 & 42.2 & 45.2 & 58.1 \\
\hline & & & rel. abund. & 100.0 & 84.8 & 84.6 & 75.9 & 68.3 & 35.3 & 35.2 & 33.8 & 29.6 & 27.1 & 19.3 & 19.0 & 18.2 & 17.8 & 11.5 \\
\hline \multirow[t]{2}{*}{5} & (Z)-2-hexenal & 855 & $m / z$ & 41.2 & 69.1 & 55.1 & 83.1 & 42.2 & 57.1 & 39.2 & 29.2 & 98.1 & 70.1 & 43.1 & 56.1 & 97.1 & 112.0 & 80.1 \\
\hline & & & rel. abund. & 100.0 & 99.4 & 95.7 & 86.8 & 59.7 & 59.5 & 58.7 & 36.0 & 31.6 & 28.8 & 26.1 & 23.7 & 21.1 & 17.7 & 17.2 \\
\hline \multirow[t]{2}{*}{6} & $(E)-2$-hexenal & 856 & $\mathrm{~m} / \mathbf{z}$ & 41.2 & 69.1 & 55.1 & 83.1 & 39.2 & 57.1 & 42.2 & 29.2 & 98.1 & 70.1 & 43.2 & 56.1 & 97.1 & 80.1 & 53.2 \\
\hline & & & rel. abund. & 100.0 & 97.1 & 94.3 & 87.4 & 60.5 & 58.7 & 57.4 & 36.9 & 32.6 & 28.3 & 27.7 & 24.1 & 21.6 & 17.0 & 14.7 \\
\hline \multirow[t]{2}{*}{7} & hexanol & 870 & $\mathrm{~m} / \mathbf{z}$ & 56.2 & 55.2 & 43.2 & 41.2 & 69.1 & 42.2 & 31.2 & 29.2 & 39.2 & 57.1 & 91.1 & 84.1 & 44.1 & 70.2 & 53.1 \\
\hline & & & rel. abund. & 100.0 & 50.6 & 48.9 & 35.8 & 35.7 & 33.1 & 16.5 & 14.3 & 10.9 & 10.3 & 6.5 & 6.1 & 4.1 & 3.4 & 2.9 \\
\hline \multirow[t]{2}{*}{8} & 2-heptanone & 894 & $\mathrm{~m} / \mathbf{z}$ & 43.2 & 58.1 & 71.1 & 81.1 & 41.2 & 59.1 & 114.1 & 99.1 & 39.2 & 55.2 & 29.2 & 42.2 & 72.1 & 85.1 & 124.1 \\
\hline & & & rel. abund. & 100.0 & 77.8 & 24.5 & 16.2 & 12.9 & 12.8 & 9.1 & 8.3 & 8.0 & 7.4 & 6.9 & 6.0 & 4.5 & 4.3 & 3.8 \\
\hline \multirow[t]{2}{*}{9} & heptanal & 904 & $\mathrm{~m} / \mathrm{z}$ & 43.2 & 55.2 & 41.2 & 70.1 & 57.1 & 44.1 & 81.1 & 71.1 & 29.2 & 133.0 & 42.2 & 39.2 & 151.0 & 99.1 & 68.1 \\
\hline & & & rel. abund. & 100.0 & 81.1 & 74.9 & 72.9 & 61.1 & 47.2 & 45.4 & 40.9 & 35.6 & 35.6 & 35.4 & 28.2 & 26.8 & 21.8 & 21.0 \\
\hline \multirow[t]{2}{*}{10} & unknown & 908 & $\mathrm{~m} / \mathrm{z}$ & 71.1 & 41.2 & 55.2 & 56.2 & 43.2 & 58.1 & 42.2 & 57.1 & 29.2 & 39.2 & 70.1 & 67.1 & 85.1 & 44.1 & 69.1 \\
\hline & & & rel. abund. & 100.0 & 55.4 & 45.8 & 38.1 & 34.4 & 33.6 & 26.0 & 23.1 & 22.2 & 18.8 & 18.0 & 16.0 & 15.0 & 14.4 & 13.1 \\
\hline 11 & unknown & 929 & $\mathrm{~m} / \mathbf{z}$ & 56.1 & 55.2 & 41.2 & 43.1 & 69.1 & 42.2 & 67.1 & 54.1 & 29.2 & 57.1 & 39.2 & 68.1 & 133.0 & 124.1 & 83.1 \\
\hline
\end{tabular}


Supplementary Table 2 (continued)

\begin{tabular}{|c|c|c|c|c|c|c|c|c|c|c|c|c|c|c|c|c|c|c|}
\hline \multirow[b]{2}{*}{ nr. } & \multirow[b]{2}{*}{ name } & \multirow[b]{2}{*}{ Kováts RI } & & \multicolumn{15}{|c|}{ most abundant fragments } \\
\hline & & & & 1 & 2 & 3 & 4 & 5 & 6 & 7 & 8 & 9 & 10 & 11 & 12 & 13 & 14 & 15 \\
\hline \multirow[t]{2}{*}{12} & (Z)-2-heptenal & 948 & $\mathrm{~m} / \mathrm{z}$ & 83.1 & 55.1 & 70.1 & 41.2 & 69.1 & 39.2 & 84.1 & 57.1 & 43.2 & 68.1 & 29.2 & 42.2 & 56.1 & 53.2 & 79.1 \\
\hline & & & rel. abund. & 100.0 & 38.5 & 32.4 & 31.1 & 21.2 & 20.0 & 14.7 & 13.0 & 12.6 & 12.1 & 11.6 & 9.9 & 9.5 & 8.5 & 6.5 \\
\hline \multirow[t]{2}{*}{13} & (E)-2-heptenal & 960 & $\mathrm{~m} / \mathrm{z}$ & 83.1 & 41.2 & 55.2 & 57.1 & 56.2 & 70.1 & 69.1 & 68.1 & 39.2 & 43.2 & 84.1 & 29.2 & 42.2 & 97.1 & 53.1 \\
\hline & & & rel. abund. & 100.0 & 73.4 & 69.4 & 55.4 & 46.9 & 45.3 & 42.3 & 39.1 & 38.1 & 26.8 & 22.4 & 19.1 & 17.4 & 14.1 & 12.8 \\
\hline \multirow[t]{2}{*}{14} & 1-octen-3-ol & 981 & $\mathrm{~m} / \mathrm{z}$ & 57.1 & 43.2 & 72.1 & 55.1 & 41.2 & 29.2 & 85.1 & 60.1 & 70.1 & 73.1 & 58.1 & 39.2 & 71.1 & 99.1 & 68.1 \\
\hline & & & rel. abund. & 100.0 & 19.8 & 18.5 & 18.0 & 13.4 & 11.9 & 10.5 & 10.4 & 8.9 & 7.9 & 6.8 & 6.7 & 6.5 & 6.5 & 5.7 \\
\hline \multirow[t]{2}{*}{15} & unknown & 989 & $\mathrm{~m} / \mathrm{z}$ & 60.1 & 73.1 & 43.2 & 41.2 & 57.1 & 87.1 & 55.1 & 45.1 & 29.2 & 99.1 & 42.2 & 72.1 & 39.2 & 61.1 & 71.1 \\
\hline & & & rel. abund. & 100.0 & 54.7 & 30.6 & 23.5 & 23.0 & 17.5 & 16.0 & 12.7 & 12.1 & 11.9 & 11.1 & 10.9 & 10.6 & 10.1 & 9.3 \\
\hline \multirow[t]{2}{*}{16} & 2-pentyl furan & 994 & $\mathrm{~m} / \mathrm{z}$ & 81.1 & 138.1 & 82.1 & 53.1 & 60.1 & 95.1 & 41.2 & 94.1 & 39.2 & 73.1 & 67.1 & 83.1 & 109.1 & 29.2 & 43.2 \\
\hline & & & rel. abund. & 100.0 & 24.3 & 24.2 & 10.2 & 7.5 & 5.7 & 5.6 & 4.7 & 4.4 & 4.4 & 3.2 & 3.0 & 2.7 & 2.7 & 2.7 \\
\hline \multirow[t]{2}{*}{17} & octanal & 1005 & $\mathrm{~m} / \mathrm{z}$ & 43.2 & 57.1 & 41.2 & 84.2 & 56.2 & 44.1 & 55.2 & 69.2 & 29.2 & 81.1 & 42.2 & 82.1 & 68.1 & 67.1 & 85.2 \\
\hline & & & rel. abund. & 100.0 & 91.8 & 88.3 & 85.9 & 83.9 & 77.3 & 74.4 & 51.2 & 44.3 & 42.5 & 41.7 & 40.5 & 36.7 & 32.8 & 32.0 \\
\hline \multirow[t]{2}{*}{18} & 2-octenal & 1062 & $\mathrm{~m} / \mathrm{z}$ & 70.1 & 55.2 & 83.1 & 41.2 & 57.1 & 69.1 & 82.1 & 39.2 & 29.2 & 42.2 & 67.1 & 97.1 & 84.1 & 56.2 & 68.1 \\
\hline & & & rel. abund. & 100.0 & 83.0 & 75.3 & 70.2 & 53.5 & 47.8 & 40.1 & 36.7 & 34.8 & 28.5 & 24.9 & 21.2 & 20.3 & 16.3 & 15.9 \\
\hline
\end{tabular}


Supplementary Table 3 Mass to charge ratios of ions from (Z)-9-tricosene impurities listed in Extended Data Table 3. For each compound, the Kováts retention index (RI) and the fifteen most abundant fragments by their mass to charge numbers are given, followed by each fragment's abundance relative to the base peak at $100 \%$ abundance.

\begin{tabular}{|c|c|c|c|c|c|c|c|c|c|c|c|c|c|c|c|c|c|c|}
\hline \multirow[b]{2}{*}{ nr. } & \multirow[b]{2}{*}{ name } & \multirow[b]{2}{*}{ Kováts RI } & & \multicolumn{15}{|c|}{ most abundant fragments } \\
\hline & & & & 1 & 2 & 3 & 4 & 5 & 6 & 7 & 8 & 9 & 10 & 11 & 12 & 13 & 14 & 15 \\
\hline \multirow[t]{2}{*}{1} & unknown & 574 & $\mathbf{m} / \mathbf{z}$ & 44.1 & 40.1 & 43.1 & 29.2 & 45.1 & 60.1 & 59.2 & 42.1 & 41.2 & 58.2 & 75.1 & 207.0 & 34.1 & 39.2 & 57.2 \\
\hline & & & rel. abund. & 100.0 & 98.1 & 57.4 & 45.4 & 42.2 & 30.6 & 30.4 & 9.8 & 8.7 & 7.8 & 6.6 & 6.1 & 4.9 & 4.2 & 4.2 \\
\hline \multirow[t]{2}{*}{2} & acetic acid & 612 & $\mathbf{m} / \mathbf{z}$ & 43.2 & 32.1 & 45.1 & 57.2 & 60.1 & 41.2 & 29.2 & 42.2 & 59.1 & 56.2 & 44.1 & 39.2 & 75.1 & 31.2 & 86.2 \\
\hline & & & rel. abund. & 100.0 & 58.6 & 56.9 & 40.6 & 40.2 & 37.9 & 27.3 & 26.9 & 23.9 & 21.1 & 18.1 & 12.2 & 10.1 & 8.7 & 8.0 \\
\hline \multirow[t]{2}{*}{3} & unknown & 678 & $\mathrm{~m} / \mathbf{z}$ & 77.1 & 45.1 & 43.2 & 56.2 & 84.1 & 78.1 & 41.2 & 74.1 & 207.0 & 55.1 & 42.2 & 29.2 & 79.1 & 57.1 & 73.1 \\
\hline & & & rel. abund. & 100.0 & 16.8 & 13.4 & 10.8 & 7.9 & 7.8 & 7.5 & 5.5 & 5.0 & 4.8 & 4.5 & 4.5 & 4.4 & 3.5 & 3.4 \\
\hline \multirow[t]{2}{*}{4} & heptane & 700 & $m / z$ & 77.1 & 45.1 & 43.2 & 56.2 & 84.1 & 78.1 & 41.2 & 74.1 & 207.0 & 55.1 & 42.2 & 29.2 & 79.1 & 57.1 & 73.1 \\
\hline & & & rel. abund. & 100.0 & 16.8 & 13.4 & 10.8 & 7.9 & 7.8 & 7.5 & 5.5 & 5.0 & 4.8 & 4.5 & 4.5 & 4.4 & 3.5 & 3.4 \\
\hline \multirow[t]{2}{*}{5} & unknown & 774 & $\mathrm{~m} / \mathrm{z}$ & 43.2 & 41.2 & 57.1 & 44.2 & 56.2 & 71.2 & 29.2 & 45.1 & 55.2 & 70.2 & 42.2 & 58.1 & 39.2 & 100.2 & 207.0 \\
\hline & & & rel. abund. & 100.0 & 80.5 & 70.9 & 69.5 & 57.7 & 53.1 & 51.7 & 36.1 & 36.1 & 34.9 & 34.5 & 32.2 & 31.4 & 16.5 & 16.1 \\
\hline \multirow[t]{2}{*}{6} & hexanal & 806 & $m / z$ & 91.1 & 60.1 & 92.1 & 41.2 & 55.2 & 42.2 & 70.2 & 73.1 & 43.1 & 39.2 & 29.2 & 45.2 & 69.1 & 57.1 & 31.2 \\
\hline & & & rel. abund. & 100.0 & 92.8 & 58.3 & 51.7 & 51.4 & 50.4 & 37.5 & 32.0 & 31.3 & 23.4 & 21.5 & 21.0 & 18.3 & 17.3 & 15.0 \\
\hline \multirow[t]{2}{*}{7} & (Z)-2-hexenal $\left.\right|^{\S}$ & 850 & $\mathrm{~m} / \mathbf{z}$ & 69.1 & 83.1 & 41.2 & 55.1 & 97.1 & 29.2 & 98.1 & & & & & & & & \\
\hline & & & rel. abund. & 100.0 & 93.2 & 78.1 & 76.6 & 44.4 & 25.8 & 6.0 & & & & & & & & \\
\hline \multirow[t]{2}{*}{8} & (E)-2-hexenal ${ }^{\S}$ & 858 & $\mathrm{~m} / \mathbf{z}$ & 41.2 & 55.1 & 69.1 & 83.1 & 29.2 & 98.1 & 97.1 & & & & & & & & \\
\hline & & & rel. abund. & 100.0 & 82.0 & 70.3 & 49.3 & 44.2 & 34.4 & 24.7 & & & & & & & & \\
\hline \multirow[t]{2}{*}{9} & hexanol & 867 & $\mathrm{~m} / \mathbf{z}$ & 56.2 & 55.2 & 43.2 & 41.2 & 69.1 & 42.2 & 31.2 & 29.2 & 39.2 & 57.2 & 84.1 & 71.1 & 70.2 & 44.1 & 91.1 \\
\hline & & & rel. abund. & 100.0 & 56.2 & 49.6 & 38.7 & 35.9 & 31.1 & 16.4 & 13.2 & 12.0 & 10.9 & 7.6 & 5.8 & 4.9 & 4.8 & 3.9 \\
\hline \multirow[t]{2}{*}{10} & 2-heptanone & 890 & $\mathbf{m} / \mathbf{z}$ & 43.2 & 58.1 & 56.2 & 41.2 & 55.2 & 70.1 & 71.1 & 39.2 & 42.1 & 29.2 & 97.1 & 114.1 & 98.1 & 44.1 & 54.2 \\
\hline & & & rel. abund. & 100.0 & 55.6 & 39.8 & 39.2 & 36.0 & 21.9 & 20.1 & 18.6 & 16.0 & 15.1 & 12.3 & 7.7 & 6.6 & 4.7 & 4.6 \\
\hline
\end{tabular}

$\S$ Ion fragment values by SIM (Selected Ion Monitoring) 
Supplementary Table 3 (continued)

$\begin{array}{ll}\text { nr. } & \text { name } \\ 11 & \text { heptanal } \\ 12 & \text { (E)-2-heptenal } \\ 13 & \text { heptanol } \\ 14 & \text { unknown } \\ 15 & \text { octanal } \\ 16 & \text { octanol } \\ 17 & \text { 2-nonanone } \\ 18 & \text { nonanal } \\ 19 & \text { octanoic acid } \\ 20 & \text { tridecane }\end{array}$

\begin{tabular}{|c|c|c|c|c|c|c|c|c|c|c|c|c|c|c|c|c|}
\hline \multirow[b]{2}{*}{ Kováts RI } & & \multicolumn{15}{|c|}{$\mathbf{a b}$} \\
\hline & & 1 & 2 & 3 & 4 & 5 & 6 & 7 & 8 & 9 & 10 & 11 & 12 & 13 & 14 & 15 \\
\hline \multirow[t]{2}{*}{901} & $\mathrm{~m} / \mathrm{z}$ & 70.2 & 44.2 & 43.2 & 41.2 & 55.2 & 57.1 & 42.2 & 71.1 & 29.2 & 81.1 & 39.2 & 86.1 & 68.1 & 96.1 & 45.2 \\
\hline & rel. abund. & 100.0 & 72.4 & 63.5 & 58.6 & 56.8 & 50.3 & 39.3 & 30.8 & 30.5 & 28.7 & 22.1 & 22.0 & 19.5 & 16.3 & 15.9 \\
\hline \multirow[t]{2}{*}{956} & $\mathrm{~m} / \mathrm{z}$ & 56.1 & 83.1 & 41.2 & 55.1 & 57.1 & 43.1 & 69.1 & 68.1 & 70.2 & 39.1 & 29.2 & 85.1 & 42.2 & 91.1 & 32.1 \\
\hline & l. abund. & 100.0 & 99.1 & 98.0 & 91.5 & 73.6 & 70.0 & 52.1 & 50.0 & 48.5 & 46.5 & 41.4 & 34.7 & 31.2 & 23.7 & 19.8 \\
\hline \multirow[t]{2}{*}{968} & $\mathrm{~m} / \mathrm{z}$ & 70.2 & 56.2 & 55.2 & 69.2 & 41.2 & 43.2 & 42.2 & 57.2 & 29.2 & 31.2 & 68.2 & 39.2 & 83.2 & 71.1 & 54.2 \\
\hline & el. abund. & 100.0 & 78.9 & 62.0 & 52.5 & 50.0 & 45.5 & 32.1 & 20.3 & 15.5 & 15.4 & 14.8 & 11.9 & 9.5 & 6.1 & 4.9 \\
\hline \multirow[t]{2}{*}{980} & $\mathrm{~m} / \mathrm{z}$ & 83.1 & 41.1 & 55.1 & 39.2 & 43.2 & 133.0 & 103.1 & 94.1 & 59.1 & 60.1 & 87.1 & 70.1 & 45.1 & 75.1 & 113.1 \\
\hline & 1. abun & 100.0 & 48.7 & 47.0 & 31.9 & 24.6 & 23.1 & 21.5 & 21.1 & 19.9 & 19.1 & 19.0 & 18.8 & 18.6 & 17.8 & 17.4 \\
\hline \multirow[t]{2}{*}{1004} & $\mathrm{~m} / \mathrm{z}$ & 43.2 & 57.2 & 84.2 & 41.2 & 56.2 & 44.1 & 55.2 & 69.1 & 29.2 & 81.1 & 82.1 & 42.2 & 68.1 & 67.1 & 85.2 \\
\hline & rel. abund. & 100.0 & 94.6 & 92.1 & 89.2 & 88.7 & 79.7 & 74.1 & 51.6 & 44.8 & 42.7 & 42.5 & 42.2 & 39.7 & 34.5 & 32.4 \\
\hline \multirow[t]{2}{*}{1070} & $\mathrm{~m} / \mathrm{z}$ & 56.2 & 55.2 & 70.1 & 69.2 & 41.2 & 84.2 & 43.2 & 83.2 & 42.2 & 57.2 & 60.1 & 68.1 & 29.2 & 73.1 & 39.2 \\
\hline & el. abund. & 100.0 & 90.8 & 75.5 & 74.7 & 72.0 & 59.0 & 57.8 & 53.8 & 42.6 & 37.9 & 28.6 & 23.5 & 23.4 & 20.7 & 18.3 \\
\hline \multirow[t]{2}{*}{1093} & $\mathrm{~m} / \mathrm{z}$ & 58.1 & 43.1 & 71.1 & 57.2 & 59.2 & 41.2 & 142.2 & 55.2 & 85.1 & 29.2 & 39.2 & 84.1 & 42.2 & 82.1 & 56.2 \\
\hline & rel. abund. & 100.0 & 71.1 & 25.1 & 22.1 & 22.0 & 15.6 & 10.4 & 9.0 & 6.3 & 6.1 & 5.8 & 5.3 & 5.0 & 4.9 & 4.3 \\
\hline \multirow[t]{2}{*}{1106} & $\mathrm{~m} / \mathrm{z}$ & 57.2 & 41.2 & 56.2 & 43.2 & 55.2 & 98.2 & 44.1 & 70.2 & 82.1 & 69.2 & 68.2 & 81.1 & 95.1 & 29.2 & 96.1 \\
\hline & rel. abund. & 100.0 & 62.1 & 58.9 & 51.8 & 49.4 & 43.4 & 43.1 & 41.6 & 37.1 & 35.7 & 32.7 & 29.5 & 29.0 & 28.5 & 27.5 \\
\hline \multirow[t]{2}{*}{1170} & $\mathrm{~m} / \mathrm{z}$ & 60.1 & 73.1 & 43.2 & 101.1 & 55.2 & 41.2 & 85.2 & 84.1 & 87.1 & 69.2 & 115.1 & 61.1 & 29.2 & 57.2 & 45.1 \\
\hline & rel. abund. & 100.0 & 78.1 & 35.1 & 31.2 & 27.7 & 27.3 & 22.0 & 21.2 & 15.7 & 13.8 & 13.1 & 12.6 & 11.9 & 10.1 & 9.9 \\
\hline \multirow[t]{2}{*}{1300} & $\mathrm{~m} / \mathrm{z}$ & 57.2 & 71.2 & 43.2 & 85.2 & 41.2 & 55.2 & 56.2 & 70.2 & 29.2 & 99.2 & 184.2 & 84.2 & 42.2 & 69.2 & 98.2 \\
\hline & rel. abund. & 100.0 & 69.6 & 62.1 & 47.1 & 28.0 & 15.5 & 15.4 & 13.8 & 10.6 & 9.4 & 8.8 & 8.8 & 8.2 & 7.6 & 7.5 \\
\hline
\end{tabular}


Supplementary Table 4 Mass to charge ratios of ions from $c$ VA impurities listed in Extended Data Table 4. For each compound, the Kováts retention index (RI) and the fifteen most abundant fragments by their mass to charge numbers are given, followed by each fragment's abundance relative to the base peak at $100 \%$ abundance.

\begin{tabular}{|c|c|c|c|c|c|c|c|c|c|c|c|c|c|c|c|c|c|c|}
\hline \multirow[b]{2}{*}{ nr. } & \multirow[b]{2}{*}{ name } & \multirow[b]{2}{*}{ Kováts RI } & & \multicolumn{15}{|c|}{ most abundant fragments } \\
\hline & & & & 1 & 2 & 3 & 4 & 5 & 6 & 7 & 8 & 9 & 10 & 11 & 12 & 13 & 14 & 15 \\
\hline \multirow[t]{2}{*}{1} & methyl acetate & 542 & $\mathrm{~m} / \mathrm{z}$ & 43.1 & 74.1 & 32.1 & 59.1 & 42.1 & 29.1 & 44.1 & 31.1 & 84.0 & 45.1 & 41.1 & 40.0 & 75.0 & 86.0 & 49.1 \\
\hline & & & rel. abund. & 100.0 & 28.0 & 12.0 & 9.5 & 9.4 & 4.6 & 3.6 & 2.1 & 1.9 & 1.7 & 1.6 & 1.5 & 1.2 & 1.2 & 0.9 \\
\hline \multirow[t]{2}{*}{2} & hexane & 600 & $\mathrm{~m} / \mathbf{z}$ & 57.2 & 43.2 & 41.2 & 29.2 & 27.1 & 56.2 & 42.2 & 39.2 & 86.1 & 28.1 & 55.2 & 15.0 & 71.2 & 58.1 & 26.1 \\
\hline & & & rel.abund. & 100.0 & 81.3 & 70.2 & 60.7 & 45.4 & 45.3 & 40.9 & 19.7 & 15.5 & 10.7 & 6.6 & 5.8 & 5.0 & 4.4 & 3.9 \\
\hline \multirow[t]{2}{*}{3} & ethyl acetate & 615 & $\mathrm{~m} / \mathrm{z}$ & 43.1 & 45.1 & 60.1 & 15.1 & 42.1 & 29.1 & 14.1 & 28.2 & 41.1 & 18.1 & 44.1 & 31.2 & 16.1 & 13.1 & 61.1 \\
\hline & & & rel. abund. & 100.0 & 90.4 & 74.8 & 17.0 & 13.0 & 8.4 & 4.8 & 4.0 & 3.5 & 2.7 & 2.4 & 2.4 & 2.3 & 2.0 & 1.9 \\
\hline \multirow[t]{2}{*}{4} & acetic acid & 618 & $\mathrm{~m} / \mathrm{z}$ & 43.1 & 45.1 & 60.1 & 15.1 & 42.1 & 14.1 & 29.1 & 28.2 & 13.1 & 16.1 & 18.1 & 44.1 & 41.1 & 31.1 & 17.1 \\
\hline & & & rel. abund. & 100.0 & 87.5 & 57.1 & 41.6 & 13.7 & 13.3 & 13.2 & 7.3 & 6.4 & 6.4 & 5.6 & 4.7 & 4.4 & 3.6 & 2.8 \\
\hline \multirow[t]{2}{*}{5} & methyl cyclopentane & 655 & $\mathrm{~m} / \mathbf{z}$ & 56.2 & 41.2 & 69.1 & 42.2 & 55.2 & 84.2 & 39.2 & 43.2 & 27.1 & 29.2 & 57.2 & 68.1 & 40.2 & 54.2 & 53.1 \\
\hline & & & rel. abund. & 100.0 & 49.4 & 35.3 & 24.6 & 23.0 & 17.4 & 13.9 & 11.1 & 9.9 & 7.1 & 6.0 & 4.0 & 3.5 & 3.1 & 2.7 \\
\hline \multirow[t]{2}{*}{6} & cyclohexane & 676 & $\mathrm{~m} / \mathrm{z}$ & 56.1 & 84.1 & 41.2 & 55.2 & 69.1 & 42.1 & 43.1 & 39.2 & 57.2 & 27.1 & 85.1 & 29.2 & 28.1 & 83.1 & 54.2 \\
\hline & & & rel. abund. & 100.0 & 71.4 & 50.5 & 30.9 & 25.8 & 25.0 & 23.0 & 14.9 & 14.0 & 11.6 & 8.5 & 8.4 & 6.1 & 4.8 & 4.8 \\
\hline \multirow[t]{2}{*}{7} & unknown & 755 & $\mathrm{~m} / \mathrm{z}$ & 44.1 & 55.1 & 83.1 & 45.2 & 41.2 & 71.1 & 75.1 & 84.1 & 29.2 & 39.2 & 43.2 & 32.1 & 46.1 & 77.1 & 69.1 \\
\hline & & & rel. abund. & 100.0 & 74.3 & 55.9 & 55.6 & 54.9 & 51.4 & 50.0 & 43.4 & 43.3 & 37.6 & 33.3 & 28.4 & 26.9 & 26.6 & 22.3 \\
\hline \multirow[t]{2}{*}{8} & hexanal & 802 & $\mathrm{~m} / \mathrm{z}$ & 44.1 & 56.2 & 41.2 & 43.1 & 57.1 & 27.1 & 29.2 & 39.1 & 45.1 & 72.1 & 55.1 & 82.1 & 42.1 & 58.1 & 67.1 \\
\hline & & & rel.abund. & 100.0 & 82.0 & 69.1 & 55.1 & 38.0 & 33.8 & 32.9 & 20.0 & 19.4 & 16.6 & 15.2 & 12.7 & 10.7 & 8.9 & 8.0 \\
\hline \multirow[t]{2}{*}{9} & (Z)-2-hexenal & 850 & $\mathrm{~m} / \mathrm{z}$ & 83.1 & 55.2 & 69.1 & 41.2 & 39.2 & 42.2 & 70.1 & 29.2 & 56.1 & 97.1 & 57.1 & 43.1 & 79.1 & 53.2 & 98.2 \\
\hline & & & rel.abund. & 100.0 & 72.1 & 56.4 & 53.3 & 45.2 & 24.0 & 21.4 & 19.6 & 18.0 & 16.7 & 14.9 & 14.8 & 13.8 & 13.3 & 11.8 \\
\hline \multirow[t]{2}{*}{10} & (E)-2-hexenal & 854 & $\mathrm{~m} / \mathrm{z}$ & 41.2 & 55.1 & 42.2 & 69.1 & 39.2 & 83.1 & 57.1 & 27.1 & 29.2 & 98.1 & 43.1 & 70.2 & 56.2 & 53.2 & 80.1 \\
\hline & & & rel.abund. & 100.0 & 61.1 & 58.1 & 57.1 & 50.1 & 48.0 & 47.0 & 43.0 & 42.0 & 26.0 & 23.0 & 17.0 & 14.0 & 9.8 & 9.6 \\
\hline
\end{tabular}


Supplementary Table 5 Calculated vapour pressure in Pascals for selected compounds of particular importance in the present study (see tables 1-3), arranged by their molecular weights. The vapour pressure values are calculated estimates based either on experimental data provided in literature (method 1) or estimates calculated with the EPI Suite ${ }^{\mathrm{TM}}$ software (U.S. Environmental Protection Agency, v4.11, June 2017; method 2 = mean values of Antoine and Grain methods; method 3 = values by the modified Grain method).

CAS

$\begin{array}{cc}\text { 000064-19-7 } & \text { acetic acid } \\ 000123-72-8 & \text { butanal } \\ 000078-84-2 & \text { 2-methylpropanal } \\ 000079-20-9 & \text { methyl acetate } \\ 001576-87-0 & (E)-2 \text {-pentenal } \\ 000141-78-6 & \text { ethyl acetate } \\ 000142-83-6 & (E, E)-2,4-\text { hexadienal } \\ 006728-26-3 & (E)-2 \text {-hexenal } \\ 016635-54-4 & (Z)-2 \text {-hexenal } \\ 004440-65-7 & \text { 3-hexenal } \\ 000066-25-1 & \text { hexanal } \\ 000111-27-3 & \text { hexanol } \\ 004313-03-5 & (E, E)-2,4-h e p t a d i e n a l \\ 018829-55-5 & (E)-2 \text {-heptenal } \\ 000111-71-7 & \text { heptanal } \\ 000110-43-0 & \text { 2-heptanone } \\ 000111-70-6 & \text { heptanol } \\ 003391-86-4 & \text { 1-octen-3-ol } \\ 000124-13-0 & \text { octanal } \\ 000111-87-5 & \text { octanol } \\ 000589-62-8 & \text { 4-octanol } \\ 063024-98-6 & \text { bombykal } \\ 000765-17-3 & \text { bombykol } \\ 000060-33-3 & \text { linoleic acid } \\ 006186-98-7 & \text { cis- vaccenyl acetate } \\ 027519-02-4 & (Z)-9 \text {-tricosene }\end{array}$

IUPAC name

acetic acid

butanal

2-methylpropanal

methyl acetate

(E)-2-pentenal

ethyl acetate

$(E, E)$-2,4-hexadienal

(E)-2-hexenal

(Z)-2-hexenal

3-hexenal

hexanal

hexanol

$(E, E)$-2,4-heptadienal

(E)-2-heptenal

heptanal

2-heptanone

heptanol

1-octen-3-ol

octanal

octanol

4-octanol

(10E, 12Z)-10,12-hexadecadien-1-al

(10E ,12Z)-10,12-hexadecadien-1-ol

$(9 Z, 12 Z)-9,12$-octadecadienoic acid

(Z)-11-octadecenyl acetate

(Z)-9-tricosene

\begin{tabular}{|c|c|c|}
\hline $\begin{array}{l}\text { molecular } \\
\text { weight }\end{array}$ & $\begin{array}{c}\text { vapour pressure } \\
(\mathrm{Pa})\end{array}$ & $\begin{array}{c}\text { calculation } \\
\text { method }\end{array}$ \\
\hline 60.05 & $1.12 \mathrm{E}+03$ & 1 \\
\hline 72.11 & $1.43 \mathrm{E}+04$ & 1 \\
\hline 72.11 & $2.21 \mathrm{E}+04$ & 1 \\
\hline 74.08 & $2.90 \mathrm{E}+04$ & 1 \\
\hline 84.12 & $1.69 \mathrm{E}+03$ & 1 \\
\hline 88.11 & $1.28 \mathrm{E}+04$ & 1 \\
\hline 96.13 & $1.72 \mathrm{E}+02$ & 2 \\
\hline 98.15 & $6.29 \mathrm{E}+02$ & 2 \\
\hline 98.15 & $6.29 \mathrm{E}+02$ & 2 \\
\hline 98.15 & $1.38 \mathrm{E}+03$ & 2 \\
\hline 100.16 & $1.41 \mathrm{E}+03$ & 2 \\
\hline 102.18 & 1.17E+02 & 2 \\
\hline 110.16 & $5.66 \mathrm{E}+01$ & 3 \\
\hline 112.17 & $2.52 \mathrm{E}+02$ & 2 \\
\hline 114.19 & $4.69 \mathrm{E}+02$ & 2 \\
\hline 114.19 & $6.55 E+02$ & 2 \\
\hline 116.21 & $3.98 \mathrm{E}+01$ & 2 \\
\hline 128.22 & $3.17 \mathrm{E}+01$ & 2 \\
\hline 128.22 & $1.99 \mathrm{E}+02$ & 2 \\
\hline 130.23 & $1.32 \mathrm{E}+01$ & 2 \\
\hline 130.23 & $4.01 \mathrm{E}+01$ & 2 \\
\hline 236.4 & $5.49 \mathrm{E}-02$ & 3 \\
\hline 238.42 & 7.59E-04 & 3 \\
\hline 280.45 & 2.03E-03 & 3 \\
\hline 310.52 & $1.96 \mathrm{E}-03$ & 3 \\
\hline 322.62 & $8.45 \mathrm{E}-03$ & 3 \\
\hline
\end{tabular}

